\title{
El clima intuido del Madrid medieval a través de sus documentos y del Libro de la Montería (siglos XIV-XVI)
}

\author{
The Climate of Medieval Madrid as Deduced From \\ Documents and the "Libro de la Montería" \\ $\left(14^{\text {th }}-16^{\text {th }}\right.$ Centuries) \\ Carlos Manuel Vera YagüE \\ Grupo Transierra \\ cmverayague@yahoo.es
}

Recibido: $13 / 10 / 2015$

Aceptado: 26/02/2016

\section{RESUMEN}

El presente trabajo pretende analizar cuáles eran las características climáticas que se sucedían en Madrid y su Tierra a lo largo del año, fundamentalmente entre los siglos XIV y XVI. Se intentará comprobar, dentro de las limitaciones que impone la documentación de la época, si en aquel tiempo se daba también un clima mediterráneo, o no, y si este ha variado mucho desde entonces. Igualmente se podrá comprobar algo que tal vez podría, aunque no debería, sorprendernos: el hombre medieval tenía muy claros muchos conceptos meteorológicos y climatológicos, aunque siempre aprehendidos con una finalidad práctica, para aplicarlos en su vida cotidiana tan cercana y dependiente de la naturaleza.

Palabras clave: Madrid, Baja Edad Media, Siglos XIV, XV y XVI, Clima y tiempo, Libro de la Montería, Climatología histórica.

\begin{abstract}
This paper analyses climatic characteristics in Madrid and surroundings throughout the year between the 14th and 16th centuries. Within the constraints imposed by the contemporary documentation available, the aim is to determine whether or not a Mediterranean climate existed in the Middle Ages, and if the characteristics of this climate have changed. In addition, I shall demonstrate that medieval people had a clear understanding of meteorological and climatic concepts, although these were applied for practical purposes in a daily life closely associated with nature and the environment.
\end{abstract}

Key Words: Madrid, Late Middle Ages, $14^{\text {th }}, 15^{\text {th }}$ and $16^{\text {th }}$ Centuries, Climate and Weather, Libro de la Montería, Historical Climatology.

Sumario: 1. Introducción. 2. El clima actual de Madrid. 3. Las «dos estaciones» del año en la Baja Edad Media y su climatología: el verano y el invierno. 3.1. La primavera intuida: el verano "temprado". 3.2. El verano intuido: el verano "caliente" o "estío". 3.3. El otoño intuido: el invierno templado u "otoñada". 3.4. El invierno intuido: el invierno "frío". 4. "Ni es fría ni caliente": la Tierra de Madrid y su clima templado. 5. Términos y conceptos medievales relativos al clima y a la meteorología. 6 . Conclusiones y reflexiones finales. 7. Bibliografía. 


\section{INTRODUCCIÓN}

Los geógrafos actuales, acostumbrados a trabajar con datos precisos, elaboran climogramas con sus grados centígrados para la temperatura, sus milímetros por metro cuadrado para las precipitaciones, su temperatura media anual, su precipitación total anual, su oscilación térmica o sus meses secos. Sin embargo, en la Edad Media no existían ninguno de estos datos, ni existían apenas en la Edad Moderna, ya que los registros continuados de todos esos parámetros se empezaron a recoger en España de forma más o menos sistemática desde la segunda mitad del siglo XVIII ${ }^{1}$.

Los historiadores que trabajamos sobre el Madrid medieval, acostumbrados a trabajar con datos en ocasiones mucho menos concisos, especialmente para el tema que ahora se aborda, podemos sin embargo intuir el clima de Madrid en la Edad Media. Y no solo porque partamos de la existencia teórica en época medieval de las mismas estaciones climáticas que hay en la actualidad y con parecidas características -esto es, el clima mediterráneo-, sino porque la documentación de la época así nos lo reafirma. Esto último no es un hecho menor, ya que en Historia todo lo no documentado, e incluso lo documentado, no está confirmado, y muchas veces debemos buscar lo obvio para argumentar lo hipotético.

Es asimismo un clima intuido, no porque la documentación no sea explícita en muchas ocasiones, sino respecto a los datos científicos cuantitativos en los que nos solemos mover en nuestros días. Intuido como cuando en el siglo XIX, sin dataciones científicas tan fiables como ahora, se apreció a través del arte paleolítico el clima frío que debieron soportar los mamuts y bisontes representados, así como los hombres que los dibujaron. O intuido a través de los calendarios románicos esculpidos o dibujados en las portadas y muros de las iglesias, como los del Panteón Real de San Isidoro de León.

El conocimiento climatológico era fundamental en el mundo preindustrial. Con menos datos cuantitativos, las personas conocían los ciclos fundamentales del clima y sus principales características, ya que en ello se basaba gran parte de su economía campesina. Sin embargo, hay que adentrarse en la terminología bajomedieval castellana y en castellano acerca del clima para comprenderla bien porque, aunque morfológicamente parecida o igual a la actual, no siempre coincide con los conceptos que le damos ahora. Así veremos que dividían el año climático en dos periodos, en el que su verano sería nuestra primavera y verano, y su invierno nuestro otoño e invierno.

Estas y otras interesantes cuestiones son las que intentaré abordar en este trabajo, usando para ello fuentes encuadradas por su abundancia en la Baja Edad Media, como el Libro de la Montería de Alfonso XI, los Libros de Acuerdos del Concejo madrileño y otros documentos de esta misma época para Madrid y su Tierra, además de las Relaciones de Felipe II elaboradas en el último cuarto del siglo XVI y nuevamente los Libros de Acuerdos pero de esta última centuria. Podremos distinguir cómo el Libro de la Montería y las Relaciones se ocupan sobre todo de cuestiones climatológicas, ya que explican el tiempo que frecuentemente solía hacer a lo largo del año en Castilla y en Madrid, respectivamente; mientras que el resto de la documentación suele hablar de aspectos meteorológicos, esto es, del tiempo que se dio puntual y circunstancialmente en un momento dado en Madrid.

\footnotetext{
${ }^{1}$ Creus Et. al., "Los estudios de Paleoclimatología”, p. 250.
} 


\section{EL CLIMA ACTUAL DE MADRID}

El clima actual de Madrid es mediterráneo continentalizado y está muy influido por las condiciones urbanas. Los inviernos son fríos, con temperaturas inferiores a los $8^{\circ} \mathrm{C}$, heladas nocturnas y nevadas ocasionales. Los veranos son calurosos, con medias superiores a $\operatorname{los} 25^{\circ} \mathrm{C}$ en julio y agosto y con máximas que a veces superan los $35^{\circ} \mathrm{C}$. La oscilación diaria es importante en la periferia urbana, pero se ve reducida en el centro de la ciudad por el efecto antrópico. La oscilación térmica anual suele estar en torno a los $19^{\circ} \mathrm{C}$. Las precipitaciones son poco abundantes, de no más de 500 $\mathrm{mm}$. al año, y se concentran en las estaciones de otoño y primavera, cuando el clima es más agradable. En invierno son menos frecuentes y, en verano, casi inexistentes ${ }^{2}$.

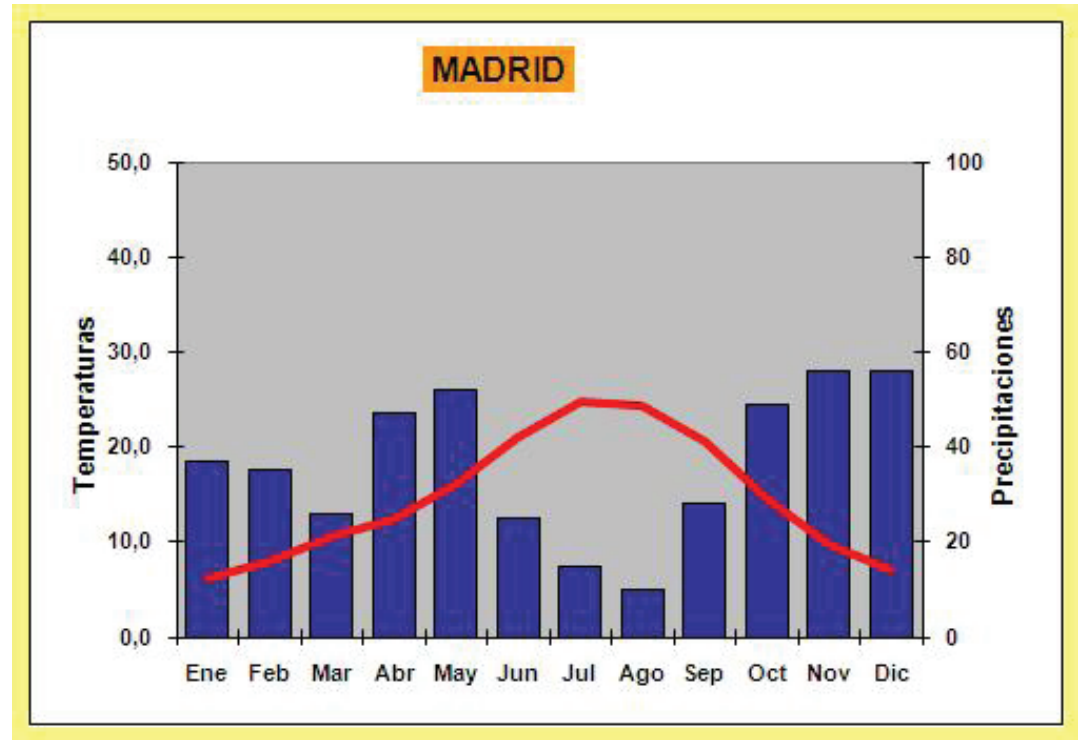

Fig. 1. Climograma actual de la villa de Madrid. (http://luismolina10.blogspot.com. es/2012/10/climograma-de-madrid.html).

\section{LAS «DOS ESTACIONES» DEL AÑO EN LA BAJA EDAD MEDIA Y SU CLIMATOLOGÍA: EL VERANO Y EL INVIERNO}

Cuando se consulta documentación bajomedieval castellana, hay una cosa que muchas veces pasa desapercibida: prácticamente solo se habla del verano y el invierno. Cuando se tratan ya específicamente temas como el clima, te das cuenta de que no aparecen nunca o casi nunca las palabras primavera y otoño³. Que las lluvias más

\footnotetext{
${ }^{2}$ http://es.wikipedia.org/wiki/Geograf\%C3\%ADa_de_Madrid.

${ }^{3}$ La palabra primavera aparece en otros idiomas, al menos en las obras literarias, como en las Crónicas del francés Jean Froissart, del siglo XIV: "cuando llegó la primavera, buena estación para quien quiere ir a 
dañinas caen en invierno, por lo que tendemos a pensar que se dan entre diciembre y marzo, con la extrañeza de que entre octubre y diciembre no se registren precipitaciones. Y es que en la Baja Edad Media el año climatológico se dividía en dos ciclos: verano, de abril a septiembre, e invierno, de octubre a marzo.

Cierto es que las cuatro estaciones sí que aparecen en ocasiones en la Edad Media castellana, aunque fundamentalmente en el ámbito literario -como, a modo de ejemplo, en algún verso del libro de Buen Amor ${ }^{4}$-. Aparecen igualmente estas cuatro estaciones en otras lenguas europeas, siguiendo la tradición clásica de la que a su vez bebe la tradición altomedieval, y que influirán después en la literatura bajomedieval ${ }^{5}$.

Todo ello nos lo aclara Covarrubias a principios del siglo XVII en su obra léxica Tesoro de la lengua castellana, o española, donde en la voz Estío dice que antiguamente se distinguían solo dos estaciones: estío y hieme, o verano e invierno. Sin embargo, en su época ya se distinguen cuatro: verano, que sería la primavera actual; estío, el verano actual; otoño e invierno. Así reza su definición de Estío:

[Del] latín aestas; una parte del año, que empieça del equinocio vernal, y se termina en el equinocio autumal, y consta de sus meses, porque antiguamente, todo el año se dividía en estío, y en hieme, o verano, e invierno: después le dividieron en quatro partes, y empeçó a llamarse estío el tiempo de los tres meses que el Sol entra en el signo de Cancro, hasta el equinocio autumal, que se causa entrando el Sol en Libra, y así se dividieron el año en quatro partes; entrando el Sol en Aries, empieça el verano; en Cancro, el estío; en Libra, el autumo; en Capricornio, la hieme, o el invierno. Estival, lo que pertenece al estío 6 .

Etimológicamente, la palabra "verano" viene del latín ver/veris. Ver significa "primavera" en latín, mientras que la palabra verano es cestiva tempora, o estación del verano. De cestiva deriva nuestra palabra estío y estival, que es como realmente deberíamos llamar los hispanohablantes al "verano", pues esta última palabra correspondería a primavera. Ahora, la palabra primavera del castellano viene de ver primus, esto es, la entrada del verano o estación previa del verano ${ }^{7}$. La palabra "otoño" deriva del latín autumnus, y esta a su vez de la composición auctus y annus; auctus es el participio del verbo augeo, que viene del griego auxo, que significa aumentar. Por tanto, parece definir que llega la plenitud del año, tal vez porque la vegetación ya está en el final de su ciclo ${ }^{8}$. La palabra "invierno" viene del latín hibernus y este de hiems, que a su vez proviene del griego cheimón, literalmente la "estación del invierno". De hibernus derivó el adjetivo calificativo castellano hibernal, que es "relativo al invier-

ultramar, mi señor William Douglas se equipó tal y como le correspondía y según le había sido ordenado", citado en Ortega Cervigón, "La medida del tiempo", p. 27. Las palabras "otoño" y "otoñada" aparecen a veces en la literatura medieval, por ejemplo en el Libro de Buen Amor del Arcipreste de Hita, del siglo XIV, y en la documentación castellana, sobre todo en la del siglo XVI.

4 "El tablero, la mesa, la danza y carretera/son las cuatro estaciones del año que te espera./Los hombres son los meses: cosa es verdadera/que andan y no se alcanzan al seguir su carrera", del Libro de Buen Amor, citado en CASTIÑEIRAs GonZÁLEZ, El calendario medieval hispano, p. 55.

5 Ibidem.

${ }^{6}$ Covarrubias Orozco, Tesoro de la lengua castellana, p. 385.

$7 \mathrm{http}$ //etimologias.dechile.net/?verano.

${ }^{8} \mathrm{http}$ ///etimologias.dechile.net/?oton.o 
no". Hiems también está asociado al frío, o tempestad, ambos representativos de esa época del año'.

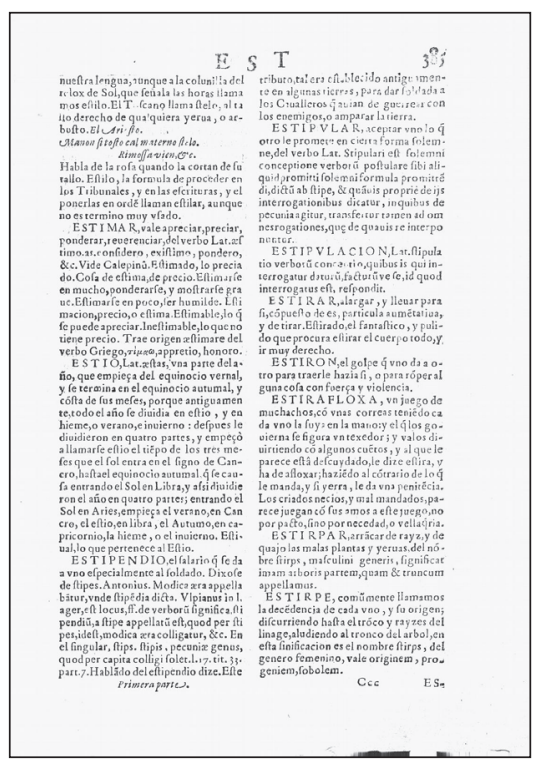

\begin{tabular}{|c|}
\hline 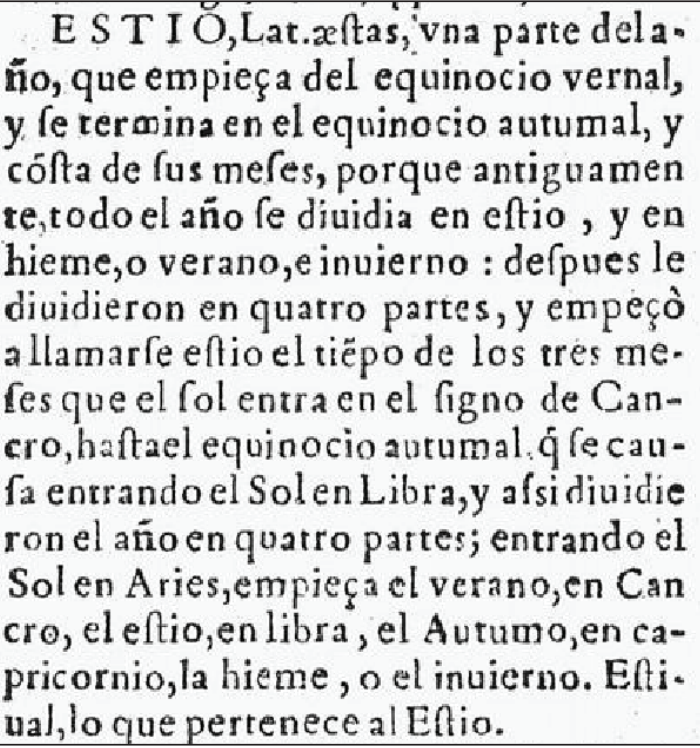 \\
\hline
\end{tabular}

Figs. 2 y 3. Página del Tesoro de la lengua castellana, o española de Covarrubias donde aparece la voz Estío. (http://fondosdigitales.us.es/fondos/libros/765/808/tesoro-de-la-lenguacastellana-o-espanola/).

La importancia de saber que en la Baja Edad Media castellana el año se dividía en verano e invierno es fundamental para el historiador, ya que si se nombran en la documentación estas estaciones debemos colegir que la datación de lo que se está diciendo corresponde a periodos más amplios que los actuales. Y, por supuesto, es clave para situar en qué meses han concurrido las circunstancias meteorológicas comentadas en los documentos, como lluvias, sequías, inundaciones, etc. En realidad, esta simplificación en dos estaciones dificulta la labor del historiador, ya que las cuatro actuales acotan más los periodos, de tres en tres meses, que las medievales, de seis en seis.

Aparte de Covarrubias en el siglo XVII, otros muchos documentos bajomedievales avalan la existencia de dos únicas estaciones, si bien algunos recalcan además las diferencias dentro de ellas, con dos fases en cada una que vendrían a coincidir más o menos con la primavera y otoño actuales.

En las ordenanzas de la ciudad de Toledo de 1418 se establece claramente la duración de ambas estaciones, al menos desde el punto de vista normativo. El verano iría del 1 de abril al 30 de septiembre y el invierno del 1 de octubre al 31 de marzo. Esto es, no coincidirían las fechas con los equinoccios y solsticios que suponen el inicio astrológico de cada una de las estaciones, y que se dan generalmente entre los días 20 y 23 de los meses de marzo, junio, septiembre o diciembre:

\footnotetext{
${ }^{9} \mathrm{http} / / /$ etimologias.dechile.net/?invierno
} 
Que desde el comienço de verano en cada anno fasta en fin del dicho verano e el dicho verano comience en cada anno primero día de abril e fenesca postrimero día de setienbre siguiente; e el invierno comience primero día de otubre e fenesca postrimero día de março siguiente ${ }^{10}$.

En estas mismas ordenanzas se establecen jornales de trabajadores de la construcción y de carpinteros, con cuantías diferentes para el invierno y el verano, siendo más cuantiosos en verano. Los maestros albañiles cobrarían 18 maravedíes/día en verano y $15 \mathrm{mrs}$./día en invierno. Sus ayudantes, u otros peones, $9 \mathrm{mrs}$. si es hombre y $4 \mathrm{mrs}$./ día si es mujer en verano, y 7 mrs./día para el peón si es hombre y $3 \mathrm{mrs}$./día si es mujer en invierno. Esto nos confirma algo obvio, que los salarios varían a cuenta de la cantidad de horas de luz y, por tanto, de horas de trabajo: más en verano y menos en invierno ${ }^{11}$. Pero además, las mayores dificultades climáticas en el invierno harían parar las obras contratadas, seguramente ante la caída de nevadas. Otras cuestiones interesantes que reflejan estas ordenanzas son el establecimiento de diferencias salariales por sexos, donde las mujeres cobran menos que los hombres, al tiempo que comprobamos que las mujeres trabajaban en actividades como la construcción; eso sí, siempre entre los ayudantes o peones, no como maestras de obra ${ }^{12}$.

Uno de los trabajos escritos que más hablan de clima en la Edad Media en Castilla es el Libro de la Montería, mandado realizar por Alfonso XI en la primera mitad del siglo XIV. El Libro de la Montería trata en su Libro III, en algunos de sus capítulos, varios territorios de la Transierra madrileña ${ }^{13}$, por lo que muchas de las informaciones generales que aparecen en sus libros I y II serían extensibles, además de a toda Castilla, a Madrid.

En el capítulo XXXV del Libro I de la Montería se confirma nuevamente la existencia de solo dos estaciones medievales: "que fabla cuales meses del año son mejores para correr, también en invierno como en verano". En este mismo capítulo se citan los meses de octubre, noviembre y diciembre como invierno, y no otoño, además de los de enero, febrero y marzo:

Decimos en esta manera que los meses que fallamos que son mejores para correr monte en invierno, que son Octubre, et Noviembre et Deciembre [...] Et naturalmiente huelen mejor los canes en este tiempo que en otro, porque es el tiempo más frío [...] et en los meses de Enero, et Febrero et Marzo si son los osos...

Y sigue con el verano, que iría de abril a septiembre:

${ }^{10}$ Ordenanzas de Toledo, ff. CLXXVIIv-CLXXVIIIr, citadas en IzQUIERDo BENITO, Precios y salarios en Toledo, p. 298.

${ }^{11}$ Teniendo en cuenta que se solían hacer dos interrupciones para comer, las jornadas de trabajo oscilarían entre ocho y nueve horas en invierno, y entre doce o trece -y hasta quince horas- en verano (ORTEGA CERVIGÓN, "La medida del tiempo", p. 18).

12 Ordenanzas de Toledo, ff. CLXXVIIv-CLXXVIIIr, citadas en IzQuIERdo BenITo, Precios y salarios en Toledo, pp. 293 y 299.

${ }^{13}$ La Transierra madrileña es una forma de denominar para la Edad Media, de forma menos anacrónica, al territorio que conforma la actual Comunidad Autónoma de Madrid. Más información sobre este concepto y el Grupo Transierra de investigación histórica, al que pertenezco, en Carrasco TeZanos y Vera Yagüe, "La organización social del espacio". 
Otrosí, en el verano los meses que son mejores para correr monte son Abril et Mayo, et de diez días por andar de Agosto en adelante, et Setiembre. Et la razón porqué, es porque en Abril et en Mayo es el tiempo temprado para los canes et para los hombres, que non es muy frío, nin muy caliente [...] Et en Junio et Julio, et en los veinte días primeros de Agosto, como quier que van engordando los venados, es el tiempo tan caliente...

En el prólogo del Libro de la Montería se señala que el Libro III menciona qué tipo de montes es mejor en cada una de esas dos estaciones: "el tercero libro fabla de los montes de nuestro señorío en cuales comarcas son, et cuales son buenos de invierno, et cuales de verano". Se habla también continuamente de qué tipo de caza es mejor en cada estación, o cómo hay que cuidar a los perros, a los que habría que sacar dos veces al día y dos a la noche "et darles siempre a comer en invierno al sol puesto, et en verano un poco ante de vísperas, por razón que nunca tengan mientes por comer de mañana"14. En definitiva, el Libro de la Montería habla continuamente de dos estaciones a lo largo del año.

Los monteros debían saber de tiempo y de clima, esto es, debían prever las condiciones de temperatura y lluvia que va a hacer durante unos días -el tiempo y las previsiones meteorológicas-y conocer qué condiciones de temperatura y lluvia suele haber en una zona según la época del año -el clima-. Así, para conocer el rastro de un venado, los monteros tendrían que tener en cuenta ambas cosas:

Otrosí [deben] conoscer bien el rastro de un venado, si es pequeño, o si es comunal, o si es grande. Otrosí saber conoscer los tiempos, ca tiempo puede facer que será un rastro pequeño et parescerá grande; et en el tiempo que es esto es este. En el tiempo que está la tierra temprada de lluvias o de nieblas será el rastro pequeño, et parescerá grande, porque por la blandura figúrase el rastro todo, et algo más de lo que es; et aun en muchos lugares resvala, et paresce muy mayor ${ }^{15}$.

El Libro de la Montería diferencia entre los tiempos húmedos y secos, sin caer en la ecuación facilona que los no habituados a tratar cuestiones climáticas o los que se han alejado de la naturaleza y del comportamiento atmosférico resuelven relacionando el tiempo seco y el calor. De este modo no solo el verano es una estación seca, sino que en la estación fría del invierno, cuando caen las heladas, la sequedad es también grande: "Otrosí en los tiempos secos que son dos, en el verano por las grandes secas, et por las grandes calenturas; otrosí en invierno en los tiempos de los muchos hielos"16.

Con todos los datos expuestos, se podrían establecer unas equivalencias entre las estaciones del año y sus denominaciones a lo largo de la historia en Castilla, aunque para las medievales me he permitido la licencia de combinar algunos de los nombres y adjetivos que aparecen en el Libro de la Montería, recogiendo las características para cada estación que subyacen en dicha obra aunque no vengan mencionados tal cual los nombro yo en la tabla. Esas características vendrían determinadas por las

\footnotetext{
${ }^{14}$ Libro de la Montería, I, capítulo I.

15 Ibidem, I, cap. II.

16 Idem.
} 
temperaturas templadas o extremas, de frío y de calor, que se suceden en el verano y el invierno:

\begin{tabular}{|l|l|l|}
\hline BAJA EDAD MEDIA & SIGLO XVII Y ANTES & ACTUAL \\
\hline Verano "temprado" & Verano & Primavera \\
\hline Verano "caliente" o "estío" & Estío & Verano \\
\hline Invierno templado u "otoñada" & Autumo & Otoño \\
\hline Invierno "frío" & Hieme o Invierno & Invierno \\
\hline
\end{tabular}

\subsection{LA PRIMAVERA INTUIDA: EL VERANO "TEMPRADO"}

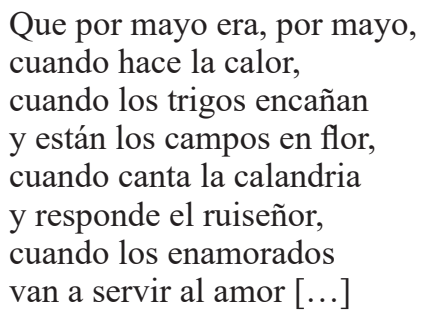

En el famoso Romance del Prisionero, anónimo castellano de época medieval, se confirma algo habitual de mayo: el aumento de las temperaturas tras el frío invierno y los primeros momentos de la primavera. Ya comentamos que el historiador no debe solo descubrir cosas, sino confirmar otras, incluido lo aparentemente obvio. También es la época en la que germinan muchas flores y plantas, tal como dice el Romance y el propio Libro de la Montería:

Porque en Abril et en Mayo es el tiempo temprado para los canes et para los homes, que non es muy frío, nin muy caliente, et los venados fallan de comer en las yerbas nuevas, et en los panes que comienzan a nascer, et van comenzando a engordar, señaladamente estos dos meses los osos comienzan a entrar en fuerza, et andan en celo, et fallará home en monte tres o cuatro juntados más que en otro tiempo; pero que en estos dos meses destorba mucho el oler a los canes las flores et las yerbas nuevas ${ }^{17}$.

Como se aprecia en la anterior cita, el Libro de la Montería señala un tiempo "temprado", esto es, templado, ni muy frío ni muy caliente, para la primavera. Hemos visto anteriormente que este mismo Libro habla del pleno verano y del invierno con heladas como estaciones secas, mientras que hay un "tiempo que está la tierra temprada de lluvias o de nieblas"18, que se correspondería con la primavera y el otoño. Esto es, son estaciones húmedas o, por lo menos, no son estaciones tan secas como las otras.

En el clima mediterráneo actual, las precipitaciones se sitúan por debajo de los 800 mm. anuales, y en Madrid están en torno a los $500 \mathrm{~mm}$. Las lluvias se concentran en los meses de primavera, otoño e invierno, con sequía estival. Sin embargo, no existe

\footnotetext{
${ }^{17}$ Ibidem, I, cap. XXXV.

${ }^{18}$ Ibidem, I, cap. II.
} 
mucha documentación medieval para Madrid que indique claramente lluvias en primavera. Lo que sí señala la documentación son crecidas de ríos en esa estación, pero ello no tiene por qué corresponder siempre con un aumento de lluvias, sino con el deshielo, o con ambas cosas a la vez.

De hecho, los ríos principales que pasan por la Tierra de Madrid nacen unos cuantos kilómetros atrás, entre 60 y 100 kms., y a unos 2.000 metros de altitud: el Manzanares en la sierra de Guadarrama, concretamente en La Pedriza, y el Jarama en la sierra de Ayllón. Ambos ríos se identifican con el régimen fluvial denominado pluvionival, esto es, sus aportes hídricos provienen de las lluvias de primavera y otoño y en menor medida de las lluvias y nevadas del invierno, pero también provienen en gran cantidad del deshielo que se produce en primavera de las nieves invernales acumuladas en esas sierras. El régimen pluvio-nival se caracteriza por tener un máximo de caudal en marzo y abril, con otro pico pluvial secundario en otoño a partir de noviembre-diciembre, el cual se extiende hasta febrero, y un estiaje en verano que se puede prolongar hasta noviembre. Esto confirmaría otra cosa que se da tanto en la Edad Media como en la actualidad: la caída habitual de grandes nevadas en invierno en las sierras del entorno de la Transierra madrileña ${ }^{19}$.

Por tanto, otra cosa reconocible en estos ríos es su irregularidad, típica de los ríos mediterráneos, con grandes diferencias de caudal según los meses antedichos, el cual en verano va prácticamente seco. De esa irregularidad dan cuenta, aunque ya en el siglo XVI, las Relaciones de Felipe II. Los distintos pueblos madrileños mencionan los ríos que atraviesan su Tierra, junto a sus características, en la pregunta 20 del cuestionario que se pasó entre los vecinos de esos lugares entre 1576 y 1579 . Casi todos los pueblos citan al Jarama como un río con un caudal regular a lo largo de todo el año, aunque con menos agua en verano y parte del otoño. El Manzanares sería un río mucho más irregular, y en verano y en la "otoñada" - ¿septiembre y octubre? - iría con poquísimo caudal o incluso seco, especialmente en agosto. Otro río que no suele salir en los documentos de Madrid, aunque sí lo citan los pueblos cercanos al mismo, es el río Guadarrama. Este nace a 1.900 metros de altitud en Siete Picos, situados también en la sierra de Guadarrama, y tendría unas características similares al Manzanares, con un caudal casi inexistente en verano. Por cierto, hay que decir que en las Relaciones sale la palabra "otoñada" de forma frecuente porque es un documento de finales del siglo XVI, cuando ya se empiezan a diferenciar cuatro estaciones $-\mathrm{o}$ al menos tres- en vez de dos.

A modo de ejemplo, ya que se podrían poner muchas más citas extraídas de las Relaciones, los vecinos de Coslada dicen del río Jarama que "es río en buen orden", los de Chamartín que "es un río que de verano y invierno lleva cantidad de agua", y los de Velilla que "es río cabdaloso bueno, que en muchos tiempos del año no se pasa sino es por barcas e por puentes" ${ }^{20}$. En cambio, del río Manzanares dicen los de Carabanchel de Arriba que es "pequeño río, no caudaloso", y los de Perales que "en tiempo de invierno y verano que el río trae agua, porque en el agosto se seca" ${ }^{21}$. Del

19 Esas nevadas en la sierra de Guadarrama vienen confirmadas en otros estudios, como el realizado sobre el puerto de la Fuenfría por RodríGuez Morales, "Viabilidad invernal".

20 ViÑAS y Mey y PAZ y Remolar, Relaciones histórico-geográfico-estadísticas, pp. 206, 217 y 666.

${ }^{21}$ Ibidem, pp. 161 y 441. 
río Guadarrama, los habitantes de Humanejos dicen que "no es río caudaloso si no es en tiempo de lluvias", y los de Majadahonda que "es río pequeño de poco agua"22.

En cuanto a las noticias meteorológicas concretas, debo exponer aquí algunas reflexiones que servirán para los hechos que vienen a continuación y para los de las próximas estaciones. La primera reflexión es que se suelen documentar los hechos excepcionales, pero no los rutinarios. Esto es, si llueve en Madrid de forma normal no vendrá documentado, pero sí se reflejará en la documentación cuando esas lluvias sean excesivas o hagan daños, al igual que las temperaturas que se salgan de lo habitual. Esto me lleva a pensar, con razón, si los datos documentados sirven para analizar el clima de la zona, o no pasan de ser episodios extraordinarios. Pero lo cierto es que, para la Edad Media y para mi tranquilidad, estos son los datos que hay para esta época y son los datos que los especialistas en climatología histórica manejan, a falta de otros. La otra reflexión es que muchas de las fechas donde se señalan noticias de inundaciones u otro tipo de circunstancia relacionada con las precipitaciones no son totalmente fiables, porque dichas fechas indican el momento en que el concejo u otro organismo trata el problema, que no tiene por qué coincidir con la fecha en la que sucedió el mismo.

Así, entre las noticias meteorológicas concretas, hay documentadas para la Edad Media en Madrid crecidas de ríos en junio de 1451 y en marzo-abril de 1484 -este año la crecida se llevó por delante el Puente de Viveros, en el Jarama-. Señala Eduardo Jiménez que no siempre tenían que ser grandes crecidas las que provocaran la destrucción de los puentes, sino también la mala construcción de los mismos o la construcción de presas y estacadas cerca de ellos, potenciando la fuerza de las inundaciones ${ }^{23}$. En abril de 1489 se acuerda la reparación del Puente de Viveros, quién sabe si por una crecida reciente o no tan reciente del río Jarama, temiendo que de nuevo "uviere caso fortituito que el río cresca e lo lieve"24. Este mismo mes de abril de 1489 el concejo trata los desperfectos "que las muchas aguas", esto es, que el agua de las lluvias, produjo en la Puerta Cerrada hasta llegar incluso a ser considerada "derribada y fecho daño"; estos daños vendrían causados porque se echaban basuras al lado de la Puerta que impedían la escorrentía correcta hacia las "lagunas"25.

En total se documentan en el Madrid medieval tres crecidas de ríos, por deshielo y/o lluvias, y un caso concreto de lluvias en la primavera. El mes de abril se repite en los documentos, tanto en crecidas fluviales como en lluvias, lo que coincidiría con el máximo de caudal en marzo-abril que vimos en el párrafo anterior que llevan los ríos madrileños, de régimen pluvio-nival. También se producen muchas crecidas del Jarama en el siglo XVI documentadas en los libros de acuerdos de esos años, como por ejemplo la ocurrida el 14 de mayo de 1568, que se llevó la barca que había en Vaciamadrid para cruzar el río ${ }^{26}$.

\footnotetext{
${ }^{22}$ Ibidem, pp. 332 y 365.

23 JimÉnez Rayado, El agua en el origen, pp. 154, 156 y 164.

${ }^{24}$ Libros de Acuerdos, 13-abril-1489, II, p. 136.

25 Ibidem, 18-abril-1489, II, p. 138.

${ }^{26}$ Alvar EzQuerra Et. al.., "Clima, técnica y poderes”, p. 160.
} 
Hay otras hipótesis, defendidas por autores como Olagüe ${ }^{27}$, que se pueden aducir para saber si en primavera y en otoño habría más lluvias y si estas eran más abundantes en la Edad Media que posteriormente, aunque pueden ser más problemáticas en cuanto a su fiabilidad. Una de esas hipótesis se refiere al uso habitual de bueyes como animales de labranza frente a mulas, rocines y asnos en Madrid, al igual que ocurre en el resto de Castilla, documentado en múltiples arrendamientos del siglo $\mathrm{XV}^{28}$ e incluso en la imagen de San Isidro arando con bueyes, la cual se conserva en el arcón gótico que cobija la Catedral de La Almudena. El uso mayoritario de los bueyes podría hacer pensar que las épocas de siembra de cereal coinciden con fuertes lluvias. Las épocas de siembra del trigo y la cebada coinciden básicamente con el otoño y la primavera, y algo también con el invierno. El trigo de otoño se cultiva sobre todo entre octubre y noviembre, y el de primavera entre febrero y abril. La cebada de invierno se siembra entre septiembre y noviembre, y la de primavera entre enero y marzo. Las hipotéticas numerosas lluvias harían más pesado el terreno al tiempo que harían surgir prados abundantes. Los bueyes necesitan de mucho pasto, y son adecuados para mover terrenos pesados con su fuerza.

Las mulas, en cambio, comen cereal o incluso paja y rastrojos, y su menor fuerza las hace más adecuadas a terrenos menos mojados. Los pros de la mula es que trabajaban más deprisa que los bueyes. En Madrid, los bueyes, novillos y mulas tenían prácticamente el mismo precio a mediados del siglo $\mathrm{XV}^{29}$, por lo que el uso de bueyes podría responder a su funcionalidad, frente a otros criterios como la propia costumbre y la falta de innovación del campesino castellano. Julián Clemente habla también del prestigio de usar bueyes, frente a los más pobres que usarían asnos o rocines ${ }^{30}$, que efectivamente tenían en Madrid un precio menor que los animales anteriormente citados $^{31}$. Las mulas empiezan a usarse más a partir del siglo XVI, lo que según la hipótesis climática que presentamos podría deberse a una disminución de las lluvias en paralelo a la «Pequeña Edad de Hielo» que comienza este siglo y se alarga hasta el siglo XIX. Esta hipótesis climática se podría añadir a la habitual tesis demográfica y productiva de la decimosexta centuria, donde el aumento de población se traduce en la necesidad de más cereal y, por tanto, de que se trabajen más rápidamente las tierras, aunque con roturaciones de peor calidad - cosa que hacen las mulas-. En todo caso, los bueyes y las mulas eran animales habituales que el campesino usaba en la Edad Media, y por eso se incorporan frecuentemente a la iconografía medieval. Así, ambos están presentes en algo tan tradicional como el portal de Belén, según observamos, entre otras muchas obras, en el Frontal del Maestro de Avià del siglo XII conservado en el Museu Nacional d'Art de Catalunya, en Barcelona.

Olagüe arguye también como prueba de una mayor cantidad de lluvias, aunque esto es tal vez aún más problemático que lo anterior, la existencia de hayedos en Madrid, que serían abundantes en esta zona y en Castilla si advertimos en cuánta documentación son citados. Incluso, según él, Cervantes nos hablaría en el siglo XVII a través del Quijote

\footnotetext{
${ }^{27}$ OlagüE, Madrid y la sequía.

${ }^{28}$ Vera YaGüe, “Un 'IPC' medieval”, pp. 175-178 y 211-214.

${ }^{29}$ Ibidem, pp. 175-178.

${ }^{30}$ Clemente Ramos, La economía campesina en la Corona de Castilla, pp. 111-115 y 152.

31 Vera Yagüe, “Un 'IPC' medieval”, pp. 175-178.
} 
de hayas más que, por ejemplo, de pinos, que es un árbol frecuente en la actualidad en tierras manchegas. El haya necesita condiciones de humedad particulares, con lluvias de más de $800 \mathrm{~mm}$. anuales, cuando la media actual en Madrid es de $500 \mathrm{~mm}$./año. Testigos actuales de esos hayedos son el de Montejo en la provincia Madrid o el de Tejera Negra en la de Guadalajara, supervivientes de una época en la que no serían excepciones a proteger. Desde finales del siglo XVI y en el siglo XVII avanzarían los pinos, al tiempo que disminuían los hayedos ${ }^{32}$. Ahora bien, podría ser que las hayas fueran otra forma de llamar a los alisos en época cervantina, que son una vegetación de ribera, o la forma de denominar a otro tipo de árbol; además, el árbol más citado en el Quijote es la encina, un árbol típico mediterráneo ${ }^{33}$.

Otro autor que ya mencioné, Eduardo Jiménez, ha estudiado las rogativas religiosas pro-pluvia - esto es, pidiendo a Dios o a algún santo que lloviese en épocas de escasez de lluvias- documentadas para Madrid, con las que comprender cómo podría ser el clima, y ha determinado que en el siglo XV son mucho más escasas que en el XVI. Esto vendría a sugerirnos un clima más cálido y lluvioso en la decimoquinta centuria y más seco y menos lluvioso en la siguiente ${ }^{34}$.

Para finalizar con la primavera, en un apartado anterior expuse que los jornales de la construcción en Toledo eran más cuantiosos en verano que en invierno, ya que se podía trabajar más horas y con mejor tiempo, lo que se traducía en un mayor número de labores realizadas. En Madrid, por ejemplo, el constructor Sancho Martín debía percibir en total un salario de $2.880 \mathrm{mrs}$. en pago a sus trabajos, pero con cantidades diarias diferentes: en enero y febrero cobraría $8 \mathrm{mrs}$./día, y de marzo a octubre 10 $\mathrm{mrs} . / \mathrm{día}^{35}$. Todos estos datos refuerzan una vez más la idea de días largos a partir de la primavera y hasta inicios del otoño, además de una meteorología más favorable: tiempo algo lluvioso, pero sin nieves, en primavera, y tiempo estable en verano, frente a las nevadas y heladas invernales. Igualmente, los contratos de obra que se hacen a maestros de obra, tapiadores, andadores de obra, etc. se suelen estipular de marzo a octubre, con un parón en noviembre, diciembre, enero y febrero ${ }^{36}$. La mayor cantidad de horas de luz a partir del «verano medieval», esto es, desde abril, está también documentada en el Libro de la Montería, aunque las citas sobre este aspecto las recojo en el siguiente apartado acerca del verano "caliente".

\subsection{EL VERANO INTUIDO: EL VERANO "CALIENTE" O "ESTÍO”}

La segunda fase del «verano medieval», que se correspondería más o menos con el verano actual, de junio a septiembre, y que aquí denomino el verano "caliente", es una época seca -como parte del invierno-y cálida. Los días, entendiendo estos por horas de luz, son más largos que en buena parte del año, tal y como sucede ahora. En algunos párrafos del Libro de la Montería se señala todo ello, además de denominar

32 OlagüE, Madrid y la sequía, pp. 23-25.

33 Morales Valverde, Flora literaria del Quijote, pp. 18, 22, 25-27 y 171.

34 JimÉnEZ RAYADO, "El agua imaginada: rogativas".

35 Archivo de la Villa de Madrid (AVM), Minutas, 21-enero-1449, tomo II, f. 4r., citado en PUÑAL FERNÁNDEZ, El registro de la documentación, p. 225.

36 Vera YagüE, 'Un 'IPC' medieval”, pp. 218-219. 
con la palabra "estío" a este periodo, cuando hablan de cómo cuidar a los perros. La palabra estío, o estiaje, indicaría la falta de lluvias junto al calor:

Pues conviene que les den a comer en el verano [a los perros], et en el estío tres veces o cuatro al día, et esto porque los días son luengos et calientes; et denles el pan remojado con agua fría, et non le den mucho, ca si non camiarloien et el camiar los enmagresce, et los face de mudar. Et si les dieren leche a beber o en migas, seerles ha bueno... ${ }^{37}$.

También se habla de "estío" cuando explica cómo curar a los perros en esa época:

Que fabla de cómo los deben melecinar [a los perros] cuando los sacaren a caza en tiempo del estío et les ficieren lazrar, et sacaren las lenguas, et refolgaren apriesa, et non fallaren agua en aquellos lugares o anduvieren ${ }^{38}$.

Sobre el enorme calor del verano da cuenta, entre otros muchos, el capítulo XXI del Libro de la Montería: "Que fabla en qué manera fagan cuando corrieren monte en tiempo muy caliente: porque en verano es el tiempo muy caliente, et los canes no son tales en verano como en invierno", siendo peor para los perros el verano ${ }^{39}$.

Se especifica que los meses realmente calurosos serían los de junio, julio y la primera veintena de agosto, con una moderación de la temperatura entre finales de agosto y septiembre:

Et en los diez días por andar de Agosto e Setiembre, andan los venados muy gordos, et fallan mucho de comer, et fállalos el home muy ciertos señaladamente a do vienen los venados a las uvas. Et en las tierras tempradas va entrando la friura, et pueden los canes estonce muy bien correr. Et en Junio et Julio, et en los veinte días primeros de Agosto, como quier que van engordando los venados, es el tiempo tan caliente, que si non es en las tierras frías además, non hay canes nin homes que puedan correr en este tiempo. Et por esto son peores estos dos meses, et las tres semanas de Agosto, que ningunos de los otros meses del año para correr monte en las más de las tierras ${ }^{40}$.

Ya señalé anteriormente que el verano es una estación árida, en la que apenas se producen precipitaciones, lo que provoca que los suelos estén secos, poco compactos y polvorientos:

Otrosí en verano, que es el tiempo seco, et polvoroso, acaesce que fará el venado el rastro en tierra seca, et polvorosa, et será el rastro dese día, et fará viento que desfará el rastro en tal guisa que dubdará el montero si es desa mañana o non [...] Otrosí porque en este tiempo es muy malo de conoscer el rastro en todos los logares, señaladamiente si es desa noche, pare mientes en las yervas que mascó o pisó, et en las ramas que quebró, et si fuere desa noche, verá la quebradura fresca, o la

\footnotetext{
37 Libro de la Montería, II, capítulo VII.

38 Ibidem, II, segunda parte, cap. X.

39 Ibidem, I, cap. XXI.

40 Ibidem, I, cap. XXXV.
} 
yerva que mascó o pisó zomienta; et si non fuera desa noche, estará la quebradura de las ramas seca et la yerva mustia ${ }^{41}$.

También en Madrid en el siglo XVI, el 7 de julio de 1581, se relata en los Libros de Acuerdos la atmósfera polvorienta del verano y su perjuicio para la salud:

Que a costa de los gastos de pestilencia, porque conviene a la salud obviar el polvo que se levanta en las calles, especial en este tiempo de estío que tanto importa que se procure remedio para que cese, el señor corregidor y comisarios de la peste provean y den orden que las tres calles principales de Atocha y Toledo y calle Mayor y Arenal se barran y se rieguen cada segundo día con odres y azacanes o de la forma que mejor les pareciere y tomando peones que barran ${ }^{42}$.

El agua, por tanto, escasea, con lo que los monteros deben acampar cerca de lugares que tengan el líquido elemento: "et si fuer tiempo de verano, que caten el agua más cerca, et fincar hi, et pensar bien sus canes..."43. Además, los monteros deben tomar las debidas precauciones y llevar agua entre sus provisiones básicas: "Otrosí, en este tiempo atal, debe mandar llevar agua en las acémilas, porque ha muchas tierras secas que por mengua de agua se podríen perder los canes" ${ }^{4}$. Solo el rocío que se produce durante la noche alivia esta sequedad, que debe ser aprovechada por los monteros madrugando lo más posible y aprovechando la mañana:

Han de madrugar más [los monteros] en el tiempo de verano que en el del invierno, porque es tiempo caliente, et con el rocío de la mañana llevará la ida mejor el montero, et levantará mejor el can. Otrosí, partir más buscas que en el invierno, porque fallen más aina; et buscar el venado a las aguas, et a las ombrías, et mandar a cada una de las buscas, que donde entiendan que podría yacer, que tomen siempre el viento, porque en este tiempo del verano es el tiempo seco, et es muy malo de fallar el rastro ${ }^{45}$.

Y de nuevo se recuerda que los días son más largos en verano, con lo que pueden cundir mejor las horas de luz de la mañana para hacer más rastreos que en otras épocas del año:

Otrosí, guardar más canes, porque si acaesciere que erraren los primeros, o dejaren con la siesta, tengan canes para cobrar el venado, porque ante que es caliente el día haya acabado su monte, o traya tan cansado el venado que se non pueda perder; que como quier que es el día del verano mayor que el del invierno, ha en el más tiempo para correr monte, que en el día del invierno. Et por esto ha mester tomar el montero más por la mañana, et haber más acucia que en otro tiempo ${ }^{46}$.

\footnotetext{
${ }^{41}$ Ibidem, I, cap. II.

${ }^{42}$ Alvar Ezquerra Et. al.., "Clima, técnica y poderes", p. 143.

${ }^{43}$ Libro de la Montería, I, capítulo XV.

${ }^{44}$ Ibidem, I, cap. XX.

${ }^{45}$ Idem.

${ }^{46}$ Idem.
} 
En el Madrid de la Edad Media apenas se registran precipitaciones en los meses de verano. Como se puede apreciar en el climograma de este artículo, los meses de junio, julio, agosto y septiembre actuales son «meses secos», según los denomina la ciencia de la climatología, conformando un «periodo de aridez». Este periodo coincide también con gran parte de la Castilla medieval, tal y como se confirma en la cita anterior del Libro de la Montería sobre los meses más calurosos. Por eso el concejo aprovecha a hacer muchas de las reparaciones de los puentes en esta época.

Tan solo hay documentadas precipitaciones para la Baja Edad Media en un día concreto de julio de 1514, en pleno verano, lo que estaría indicando el carácter de lluvia puntual y, seguramente, torrencial, ya que provoca daños en una casa. Es interesante este dato, porque generalmente cuando la documentación indica lluvias las sitúa en periodos más largos y menos acotados, como el invierno o durante determinados meses. De hecho, en el presente documento se habla de que cayó "agua", en singular, y no "aguas" en plural como suele ser habitual. Así, lo más probable es que esta lluvia de julio sea una lluvia de convección, esto es, una típica tormenta de verano, provocada por el ascenso brusco de aire cálido con aportes de humedad, formado generalmente ante un fuerte calor, que al llegar en altura a una zona más fría de la atmósfera se condensa y precipita de forma intensa. Concretamente, Antón Franco y sus vecinos se quejan de que sus casas se pueden hundir a causa de la lluvia caída el domingo 6 de julio, cuya agua fue retenida por un muladar inadecuado cercano:

Acordaron que, porque están senbrados los lugares donde sechan estiércol e que no lo echan en otras partes, e se quexan Antón Franco e los otros, sus vecinos, que a causa del muladar que se haze a las puertas de casa del dicho Antón Franco se le uviera de hundir su casa, con el agua que hizo ayer doming $0^{47}$.

Esta falta de lluvias provoca la caída radical en verano del caudal de los ríos que pasan por Madrid, como ya expuse en el anterior apartado sobre la primavera y el régimen fluvial de los ríos mediterráneos. Las Relaciones de Felipe II indican que el caudal del Manzanares y del Guadarrama era especialmente bajo o nulo en verano, mientras que el Jarama no solía secarse en esta época. Así, los vecinos de Chamartín "van a moler en tiempo de invierno al río que tienen dicho de Madrid [Manzanares]" y en verano van a moler al río Jarama "porque de verano el río de Madrid no trai agua para poder moler"; los de Alcorcón, dicen que el Manzanares "es río de poco agua de ordinario, y la que tiene es de las lluvias del invierno, porque al verano trae poco agua de su propio natural, que es como un arroyo"; los de Pozuelo de Aravaca dicen que "es río de poco agua en tiempo de agosto"; y los de Villaverde que "es río de poco agua, y se seca algunos años" lo recuerdan diversos poetas del Siglo de Oro, o el famoso comentario que en esa misma época hizo el embajador alemán Juan de Rhebiner sobre el río: "navegable a caballo y en coche por espacio de cuatro o cinco meses"49. Del río Guadarrama, los vecinos de Las Rozas señalan "que no es río caudaloso, porque en tiempo de agosto

\footnotetext{
47 Libros de Acuerdos, 7-julio-1514, V, p. 288.

48 ViÑAs y MEy y PAZ y Remolar, Relaciones histórico-geográfico-estadísticas, pp. 39, 217,475 y 732.

49 VÁzquez Fernández, "De cómo Tirso se ríe del río Manzanares”, p. 1796.
} 
se suele secar el dicho río". Se aprecia una y otra vez que, dentro del verano, agosto es especialmente árido: en este mes se secan los ríos o, como señalan los vecinos de Cobeña, "en tiempo de agosto llegan algunos años a necesidad de agua para beber las gentes y ganados" 50 .

La irregularidad de los ríos se puede intuir igualmente a través de la existencia en la toponimia medieval madrileña de nombres relacionados con periodos de estiaje, como Valseco. Este nombre da idea de estaciones en las que algunas zonas o arroyos se secan anualmente, ya que es un topónimo de tipo geográfico fijado a un lugar porque responde a sus características habituales, aunque en otras estaciones llevaría agua. Así tenemos en la Tierra de Madrid los topónimos de Huelga de Valseco, Arroyo de Valseco, Piélago de Valseco -hacia el río Jarama, por la aldea de Dos Casas-, o Valsequillo - por el camino de Pozuelo- ${ }^{51}$.

Sin embargo sí existen numerosas lluvias puntuales y torrenciales que provocan inundaciones y crecidas de ríos a finales del verano, sobre todo en septiembre, reseñadas en los Libros de Acuerdos en el siglo XVI. Encontramos de este modo una fuerte inestabilidad atmosférica, que en las postrimerías del verano y durante el otoño es mayor debida a la generación de precipitaciones por el aporte de vapor de agua que proporciona la energía acumulada en el mar Mediterráneo. También podrían ser algunas de esas precipitaciones unas lluvias de convección por acumulación de calor y humedad, como la que vimos en julio de 1514, pero con una condensación superior al ser el tiempo en septiembre algo más fresco e inestable que en julio. Estas precipitaciones convectivas son típicas también ahora en el mes de septiembre para nuestra zona de estudio, y solo algunas de ellas, las más tardías dentro del mes de septiembre, podrían corresponder a la entrada de las primeras borrascas que anuncian el otoño. La actividad convectiva es asimismo apreciada por Teresa Bullón en las crecidas estivales de los ríos Tajo y Jarama en la segunda mitad del siglo XVI ${ }^{52}$. Los ejemplos documentados acerca de ello son numerosos: en agosto de 1581, el concejo de Madrid intenta que "las avenidas del agua no hagan el daño que han comenzado" en unas obras entre el Prado y la calle de Atocha ${ }^{53}$; en septiembre del mismo año de 1581 se da la noticia, aunque documentada el 29 de noviembre, de un "turbión" o aguacero con viento fuerte, intensísimo y breve, que arrasa la fuente de El Prado ${ }^{54}$; el 28 de septiembre de 1562, las lluvias amenazan con llevarse el Soto de la Sopeña ${ }^{55}$; las de septiembre de 1579 obligan a ordenar al concejo, el 14 de ese mes, la demolición de unas almenas de la muralla que iban a ceder por dichas lluvias ${ }^{56}$; el 23 de septiembre de 1587, se manda paralizar las obras de reconstrucción del embarcadero del Jarama por las lluvias ${ }^{57}$; el 17 de septiembre de 1590 se reseña que "estando como se está al fin del mes de septiembre y comenzado a embarrar los caminos con las lluvias que

\footnotetext{
50 Viñas y MeY y PAZ y Remolar, Relaciones histórico-geográfico-estadísticas, pp. 185 y 541.

51 Vera Yagüe, "Paisaje y toponimia en la Tierra de Madrid medieval", pp. 242, 246, 248 y 252.

52 Bullón Mata, “Avenidas fluviales y precipitaciones”, p. 85.

${ }^{53}$ Documento del 11 de agosto de 1581, en Alvar EzQuerra Et. al., "Clima, técnica y poderes", p. 142.

54 Ibidem, p. 181.

55 Ibidem, pp. 177-178.

56 Ibidem, p. 180.

${ }^{57}$ Ibidem, p. 182.
} 
han caído siendo el año como es antes estéril que abundoso"58; el 19 de septiembre de 1593 se producen fuertes lluvias dentro de la villa de Madrid $^{59}$; y las precipitaciones del 3 de septiembre de 1574 provocaron también la crecida del Jarama:

En este ayuntamiento [día 16 de septiembre de 1574] el señor Francisco de Herencia dijo que con la avenida que vino por el río de Jarama el viernes pasado, tres de este mes [de septiembre] le han dicho que se descubrieron tres o cuatro arcas de las que se empedraron en la puente de Viveros y que es necesario que se reparen y aderecen ${ }^{60}$.

Hay que repetir de nuevo lo que ya dije para la primavera sobre jornales y contratos. Los jornales son más altos entre marzo y octubre, y los contratos de obra se estipulan fundamentalmente en ese periodo. Esto lleva a intuir el tiempo estable del verano y sus días más largos, como he podido documentar a lo largo del presente apartado.

Por último, el elevado y continuo calor del verano que hace madurar, entre otras cosas, al cereal, se adivina en muchísimas ocasiones en la documentación a través de las cosechas que se realizan en esta estación del año, cuyo fruto es entregado en "Santa María de Agosto" - el 15 de agosto-. También el Libro de la Montería señala que el verano es la época "de los panes", esto es, del cereal. De hecho, la mayor parte de las tierras agrícolas en la Tierra de Madrid están ocupadas por trigo y cebada, seguidas de lejos por los viñedos, ambos cultivos mediterráneos de secano. Lo que no se documentan son tierras dedicadas a olivos, el otro cultivo con el que se cerraría la trilogía mediterránea clásica ${ }^{61}$. La continentalidad y frialdad de estas tierras en algunas épocas del año, unido a la falta de tradición olivarera en el Madrid y la Castilla medievales frente a regiones como Andalucía, podrían explicar la falta de este cultivo en esta época ${ }^{62}$.

\subsection{EL OTOÑO INTUIDO: EL INVIERNO TEMPLADO U "OTOÑADA"}

En octubre empezaba el invierno medieval, y se alargaba hasta finales de marzo. Como ya he comentado reiteradamente, no se distinguía en los documentos como ahora entre otoño e invierno. Esto se comprueba una vez más en el Libro de la Montería:

Decimos en esta manera que los meses que fallamos que son mejores para correr monte en invierno, que son Octubre, et Noviembre et Diciembre. Et la razón porqué, es porque en estos tres meses también los puercos como los osos fallan bien de comer, et andan gordos et pesados, et por la mucha vianda que fallan son muy buenos de fa-

${ }^{58}$ Ibidem, p. 183.

${ }^{59}$ Ibidem, p. 184.

${ }^{60}$ Ibidem, p. 161.

${ }^{61}$ Vera YAGÜE, "Un 'IPC' medieval”, pp. 162-170 y 195-205.

${ }^{62}$ Los olivos son árboles mucho menos resistentes al frío que el viñedo o que otros tipos de árboles, como el almendro. Unas heladas que acaben, aunque sea en un lugar y momento concreto, con viñedos y almendros, pueden acabar con los olivos de esa misma zona durante décadas (GrOve y RACKHAM, The nature of Mediterranean Europe, p. 131). 
1lar. Et naturalmiente huelen mejor los canes en este tiempo que en otro, porque es el tiempo más frío. Et en los meses de Enero, et Febrero et Marzo si son los osos, yacen echados lo más de este tiempo, et cuando salen, andan mucho, et son muy malos de fallar, et son muy magros ${ }^{63}$.

Sin embargo siempre hay excepciones, y en el mismo Libro se usa la palabra "otoñada" para distinguirla del pleno invierno, si bien es posible que con este término se refiera a septiembre y la parte inicial del otoño, y no a todo el periodo actual que comprende esta estación:

[A los perros] denles a comer en la otoñada, et en el invierno, una vez cada día, cuando fuere el sol puesto, o ante un poco; ca si madrugasen con ellos a caza, non les faciendo esto, serían flacos, et tristes, et non cazarían bien ${ }^{64}$.

Muchas de las cosas que dije para la primavera, las podría trasponer para la estación del otoño. Es esta también una estación templada y algo húmeda. Y la problemática hipótesis del uso habitual en Madrid de los bueyes de labranza en vez de mulas, que demostraría que las tierras eran pesadas a causa de las lluvias en primavera, se podría aplicar al otoño, en el que también se siembran, incluso en mayor cantidad, tanto el trigo como la cebada.

Los ríos Manzanares y Jarama, recordemos que de régimen pluvio-nival, tienen en la actualidad un pico de crecidas en otoño a partir de noviembre, si bien menor que en primavera. Aunque las siguientes líneas pueden contradecir algunas de las cosas expuestas hasta ahora, parece que no toda la estación del otoño era tan húmeda. Seguramente, desde septiembre hasta finales de octubre era más bien seca, como atestiguan las Relaciones de Felipe II del siglo XVI. En estas se comenta que el estiaje de los ríos empieza en verano pero se prolonga durante la otoñada o "toñada". Sobre el Manzanares, los vecinos de Perales dicen que "tiene aguas las que ha menester del río que tengo dicho, eceto en toñada que se seca el dicho río, y en este tiempo nos proveemos de algunas fuentes que orilla del dicho río salen cuando el río falta"; mientras, los de Getafe señalan que en "el mes de junio no pueden moler los molinos por falta de agua, así es río de poco en agosto y toñada" ${ }^{65}$. Podemos comprobar en estos extractos de la documentación y en otros que se citan en este artículo, de hecho de aquí saco estas conclusiones, que en el siglo XVI llaman "otoñada" a lo que viene tras agosto, esto es, a septiembre, y, posiblemente, a las primeras semanas del otoño.

Mientras, en el río Jarama, que como se vio tenía un caudal más regular que el Manzanares durante todo el año, los Libros de Acuerdos del Concejo madrileño de la decimosexta centuria sí le documentan aportes de agua en la primera mitad del otoño: en noviembre de 1579, la crecida del Jarama "se había llevado un pedazo de la tajada que esta villa había hecho por encima de la barca de Vaciamadrid"; en octubre de 1581, se hunde la barca de Arganda en este río; en octubre y noviembre de 1593 vuelve a crecer el río Jarama y a llevarse nuevamente la barca de Arganda, dañando a la barca de

${ }^{63}$ Libro de la Montería, I, capítulo XXXV.

${ }^{64}$ Ibidem, II, segunda parte, cap. VII.

65 ViÑas y Mey y PAZ y Remolar, Relaciones histórico-geográfico-estadísticas, pp. 287 y 441. 
Madrid y a la de Vaciamadrid; y en octubre de 1594 se saca la barca de Vaciamadrid del río antes de que se la llevase un riada ${ }^{66}$.

En este mismo siglo se dan diversos episodios, pero muy puntuales, de riadas en otoño en la villa de Madrid: en 1576 y en noviembre de $1579^{67}$. La escasez de episodios de riadas y los pocos aportes de agua del río Manzanares podrían confirmar un otoño algo seco para esta zona en las primeras semanas del otoño, al menos en el siglo XVI, lo que en parte se contradice por las crecidas del río Jarama aquí analizadas.

En relación a la temperatura, los mismos lugareños de Perales comentan que es su pueblo "algo cálido de agosto y otoño", o sea, el otoño sería más bien caluroso -si bien solo señalan esto en esta aldea-, de lo que se podría colegir que además se diera escasez de lluvias y el consiguiente poco caudal de los ríos que hemos visto reiteradas veces para esta época en el siglo $\mathrm{XVI}^{68}$. Aunque, finalmente, queda claro que en otoño va refrescando el tiempo, como señala el Libro de la Montería, ya desde finales de agosto y septiembre: "Et en las tierras tempradas va entrando la friura, et pueden los canes estonce muy bien correr" 69 .

Centrándome de nuevo en aspectos más puntuales, sobre todo en incidencias meteorológicas acaecidas en la Edad Media, la Crónica de Juan II de Hernán Pérez de Guzmán relata que, cuando el rey estaba en la villa de Madrid, se dieron muchas "aguas e nieves" aquí y en otros lugares de Castilla entre finales de octubre de 1434 y enero de 1435 -concretamente desde dos días antes de Todos los Santos hasta el 7 de enero-, que provocaron la muerte de personas y ganados, derruyeron edificios y anegaron caminos y campos, los cuales quedaron impracticables para las cosechas y provocaron hambrunas en "que más de quarenta días toda la gente comía trigo cocido por mengua de harina"70. Otro temporal de lluvias se desarrolló en Madrid entre el 29 de octubre de 1438 y el 29 de enero de $1439^{71}$. Todos esos años coinciden con una época de inviernos severos en la Europa central y occidental durante la década de 1431-1440 ${ }^{72}$. En octubre de 1449 se documentan fuertes lluvias, con daños en el sótano-bodega de la casa del curtidor madrileño Alonso Sánchez ${ }^{73}$. En septiembre de 1499 se denuncian destrozos en molinos, presas y puentes del Manzanares y del Jarama causados "con las muchas aguas del ynvierno pasado" -que abarcaría de octubre a marzo de 1498-1499-, y se pide que se arreglen antes de que vuelva nuevamente el invierno. Esto es, temen este periodo, con lo que debían ser habituales las lluvias abundantes durante el mismo:

Que con las muchas aguas del ynvierno pasado apenas quedó molino en la ribera del río [Manzanares] que no se cayese la mayor parte dél e que quebró todas presas dellas e que de la puente que se llama Toledana se cayó la mayor parte [...] estaba tan

${ }^{66}$ Alvar Ezquerra Et. al., “Clima, técnica y poderes”, pp. 161, 181 y 183-184.

${ }^{67}$ Ibidem, pp. 180-181.

68 Viñas y Mey y Paz y Remolar, Relaciones histórico-geográfico-estadísticas, p. 441.

${ }^{69}$ Libro de la Montería, I, capítulo XXXV.

70 IzQuierdo Benito, Precios y salarios en Toledo, p. 42; Font Tullot, Historia del clima en España, pp. 64-65; Sabaté i Curull, "Natura i desenvolupament", p. 14; Montero Vallejo, "Un siglo de crisis en Madrid", p. 123.

71 Font Tullot, Historia del clima en España, p. 65.

72 Ibidem, p. 62.

73 JimÉnEZ RAYADO, El agua en el origen, pp. 154 y 156. 
dañado que si no se reparava se acabarya todo presto de caer e que allende desto el río de Xarama fizo tanto daño en la puente que dizen de Biberos ques desta villa ${ }^{74}$.

Ya antes de esta disposición, en mayo de 1499, el concejo había mandado hacer un repartimiento para reparar esos mismos puentes ${ }^{75}$. Una vez más, surge la duda de si estas lluvias documentadas en 1499 se producen entre octubre y diciembre del año anterior o entre enero y marzo, o bien a lo largo de esos seis meses, ya que el invierno agrupa a todos ellos.

Si recopilamos los datos expuestos hasta ahora para el otoño se documentan, más o menos, cuatro momentos de fuertes lluvias y, aparentemente, ninguna crecida de ríos por otras circunstancias que no fuesen las precipitaciones en la decimoquinta centuria. Cuantitativamente son el mismo número de incidencias meteorológicas documentadas en otoño que en primavera, aunque en este último periodo son más las crecidas de los ríos -tres en total- que las lluvias documentadas. Esto reiteraría el aporte a los ríos proveniente del deshielo en primavera, mientras que en otoño el aporte vendría casi exclusivamente de las lluvias o incluso de las primeras nevadas que anuncian el invierno.

Los jornales en el sector de la construcción son más bajos en otoño e invierno, esto es, en el «invierno medieval». Incluso los contratos de obra no suelen contemplar algunos meses de otoño, concretamente ni noviembre ni diciembre -ni generalmente enero y febrero-, ya que como vimos con anterioridad dichos contratos se estipulan en su mayoría de marzo a octubre. Esto nos lleva a pensar no solo en la disminución progresiva de horas de luz para trabajar en otoño, sino a plantear la hipótesis de un empeoramiento de la climatología, con lluvias y sobre todo nieves y heladas, que posiblemente se anticiparían a las fechas en que se dan en la actualidad -en diciembre y enero-, y empezarían a caer desde noviembre. La nieve y el hielo dificultarían sobremanera la ejecución de las obras, y harían impracticables los caminos por donde se transporta el material de construcción. En el invierno «frío» se daría la misma o peor situación meteorológica.

\subsection{EL INVIERNO INTUIDO: EL INVIERNO "FRÍO"}

La segunda fase del «invierno medieval» se correspondería más o menos con el invierno actual, de diciembre a marzo, al que aquí denomino como invierno "frío". Es esta una época que compagina periodos húmedos debidos a las numerosas lluvias y nieves que caen, al menos en Madrid, con otros secos cuando predominan las heladas. Asimismo es una estación fría donde los días, entendiendo de nuevo a estos por horas de luz, son más cortos que en otras estaciones del año, tal y como sucede ahora.

De la sequedad y el frío habla en diversos momentos el Libro de la Montería: “tiempos secos que son dos, en el verano... otrosí en invierno en los tiempos de los muchos hielos"76. De este modo, se puede apreciar uno de los fenómenos de esta

\footnotetext{
${ }^{74}$ Archivo General de Simancas (AGS), Registro General del Sello (RGS), Granada 15-septiembre-1499,

75 Libros de Acuerdos, 23-mayo-1499, IV, p. 107.

${ }^{76}$ Libro de la Montería, I, capítulo II.
} f. 7 . 
época, que son las heladas. Este mismo frío y heladas provocarían la disminución de alimento en los bosques, por lo que los animales están más delgados y es peor la caza que en el otoño:

Decimos en esta manera que los meses que fallamos que son mejores para correr monte en invierno, que son Octubre, et Noviembre et Diciembre... Et naturalmiente huelen mejor los canes en este tiempo que en otro, porque es el tiempo más frío. Et en los meses de Enero, et Febrero et Marzo si son los osos, yacen echados lo más de este tiempo, et cuando salen, andan mucho, et son muy malos de fallar, et son muy magros. Otrosí, los puercos son en este tiempo más magros que en todo el año, et como non fallan de comer, son peores de fallar que en otro tiempo ${ }^{77}$.

Las lluvias y nevadas en pleno invierno se documentan en Madrid, directa o indirectamente, a través de sus ríos y de otras apreciaciones climáticas. Por una parte, si se da por sentado que los ríos Manzanares y Jarama crecen en primavera por el deshielo de la nieve de la sierra, es porque obviamente caerían nevadas en los meses previos de invierno. Por otra parte, las Relaciones de Felipe II señalan claramente la caída habitual de nieves, aunque hay que recordar que este documento se enmarca en el siglo XVI, que es un siglo más frío que los anteriores. Por tanto, las crecidas fluviales estarían producidas por la pluviosidad invernal a la que se unirían las nevadas a baja cota, las cuales se derretirían al poco tiempo, mientras que las caídas en las cotas más altas se acumularían hasta su deshielo en la siguiente primavera.

En concreto, en las Relaciones se confirma la existencia de nevadas en la estación fría del año, especialmente en la sierra, que son recogidas por el río Jarama, ya que "de invierno trae más agua Xarama porque corre sierras que tiene más acogidas de nieve que acuden a Xarama y por eso de invierno trae más agua"78; los vecinos de Cobeña dicen de este mismo río "que en tiempo de nieves y lluvias es muy caudaloso y peligroso, y que en tiempo seco es río de poco agua"; los de Fuencarral comentan que "es un río de invierno y verano trai harta agua"; los de Ribas señalan que "es buen río, que en tiempo de invierno por las crecientes y verano no se puede pasar [vadear], aunque hay barcas en él, si no es por puente"79. De hecho, en los Libros de Acuerdos con fecha del 3 de enero de 1565 se confirma la fuerza que lleva el río Jarama, el cual se ha llevado por delante el Puente de Viveros ${ }^{80}$. Del río Manzanares, la gente de Getafe contesta en las Relaciones que "es río que [en] invierno trae agua en razón de la lluvia y de la nieve", esto es, igual que el Jarama, recoge agua de las nevadas y lluvias invernales. Y del río Guadarrama, los de Boadilla señalan que "que en invierno trae mucho agua, y en el verano poca" $"$. Todos estos datos confirman una vez más el régimen pluvio-nival de todos estos ríos que cruzan la Tierra de Madrid, al igual que confirman el mayor caudal del Jarama frente a los demás.

Sin citar ningún río, los lugareños de Fuenlabrada comentan en las Relaciones que en su aldea "hay dos lagunas que recogen agua de invierno para mucha parte del

\footnotetext{
77 Ibidem, I, cap. XXXV.

78 Relaciones topográficas, p. 620.

79 Viñas y Mey y Paz y Remolar, Relaciones histórico-geográfico-estadísticas, pp. 185, 257 y 525.

80 Alvar EzQuerra Et. al.., "Clima, técnica y poderes”, p. 178.

81 Viñas y Mey y Paz y Remolar, Relaciones histórico-geográfico-estadísticas, pp. 105 y 287.
} 
verano" 82 , mientras que los vecinos de Chamartín expresan la temperatura habitual a lo largo del año en su aldea, reafirmando una vez más la existencia de nevadas: "la calidad de la tierra en tiempo de invierno es fría, a causa de estar ocho leguas de la sierra, donde ordinario por el invierno hay mucha nieve, y en verano es tierra y lugar templado por la misma razón" "83.

Volviendo a los hechos meteorológicos acaecidos puntualmente en Madrid en el siglo XV, se documentan: "aguas e nieves" en el invierno de 1434-1435 y fuertes lluvias en el invierno de 1438-1439 -citados ambos periodos también en el apartado del otoño-; crecidas en el río Jarama en enero y febrero de 1481, donde había sido anegada por "el agua en estas abenidas pasadas" la zona del Negralejo, dedicada a pasto de ganado ${ }^{84}$; en febrero de 1484 el concejo concede la franquicia de por vida de algunos impuestos y obligaciones a Sancho el odrero, por salvar "pasando el río con tan grandes fríos e fortunas" a catorce personas que habían quedado aisladas en los sotos de Migas Calientes y de Mohed al crecer el Manzanares ${ }^{85}$; $y$ en febrero de 1492, se registran daños que "las abenidas" han hecho en el prado de Tocha ${ }^{86}$.

En resumen, se dan tres referencias concretas documentadas en la Baja Edad Media para Madrid de crecidas de ríos, y dos de lluvias y nieves en el invierno. Todas las crecidas se documentan en febrero, y solo una parte de ellas en enero. Es el mismo número de crecidas que en primavera, aunque en esta estación muchas de ellas vendrían causadas al derretirse las nieves invernales, concretamente las caídas a mayor altitud. Bullón llega igualmente a la conclusión de que las crecidas en las cuencas de los ríos Tajo y Jarama en el siglo XVI ocurren dos veces cada año: de octubre a enero, sobre todo en invierno "cuando hay nieve en la sierra", que parecen ser las crecidas de mayor caudal, y otras en primavera, entre marzo y mayo ${ }^{87}$. En los Libros de Acuerdos del siglo XVI también se refleja el temor, el 27 de octubre de 1564, ante "las avenidas de invierno" que podrían llegar, para lo que el concejo ordena quitar las estacadas de los ríos; y se documentan "avenidas y crecientes" dentro de Madrid en enero de $1597^{88}$.

Otra cualidad del clima madrileño es la influencia que recibe de la sierra de Guadarrama en cuanto a la temperatura, lo que haría que fuera más frío y más continental que en otras zonas de Castilla. Ya lo señalaban en las Relaciones de Felipe II los vecinos de Chamartín en la respuesta expuesta líneas arriba, pero también lo perciben así los vecinos de La Alameda, que dicen de su lugar que es "tierra templada, aunque participa más de fría a causa de la poca distancia hasta la sierra", mientras que los de Barajas señalan que su tierra es "algo fría por la poca distancia a la sierra" 89 . Curiosamente, La Alameda y Barajas tienen parecida opinión, ambos están muy cerca uno de otro y cerca de Chamartín, y ambos conforman el señorío de los Zapata. En general,

\footnotetext{
82 Ibidem, p. 266.

83 Ibidem, p. 217.

${ }^{84}$ Libros de Acuerdos, 7-febrero-1481, I, p. 70.

85 Ibidem, 9-febrero-1484, I, p. 294.

${ }^{86}$ Ibidem, 13-febrero-1492, II, p. 323.

87 Bullón MATA, “Avenidas fluviales y precipitaciones”, pp. 81-82.

${ }^{88}$ Alvar Ezquerra Et. al.., "Clima, técnica y poderes”, pp. 165 y 184.

89 ViÑAS y Mey y PAZ y REMOLAR, Relaciones histórico-geográfico-estadísticas, pp. 15 y 92.
} 
los demás pueblos refieren al frío que hace en el invierno a la vez que al calor del verano, y no achacan este frío a la cercanía de la sierra, aunque tenga influencia cierta.

Siguiendo con el frío intenso, cerca de Madrid se documentan heladas en el Tajo, supuestamente en los inviernos del más gélido siglo XVI, en los años 1530 y $1536^{90}$. Según Ignacio Olagüe, los techos inclinados de pizarra como los de El Escorial o Madrid darían idea de grandes nevadas. La inclinación de esos techos haría resbalar la nieve más fácilmente hacia el suelo, ya que si no la nieve acumulada y su peso podían provocar el hundimiento de los tejados ${ }^{91}$. Sin embargo, creo que este tipo de cubiertas que se impone sobre todo en el siglo XVI hay que relacionarlo más con la influencia flamenca en la arquitectura de la época de los Habsburgo. Por otra parte tenemos ejemplos constructivos cercanos en Segovia, aunque no documentados en la Edad Media para Madrid, del uso de tejas árabes simples, esto es, poniendo solo la cara de la teja cóncava inferior y no la convexa superior, facilitando así la escorrentía de la nieve. También habla Olagüe de la popularidad de los helados madrileños, que usan la nieve acumulada durante todo el año en los pozos de nieve de la sierra. Pero tampoco están documentados los helados en la Edad Media -iojalá!-, al menos con tal nombre. Ya en el siglo XVIII, con Carlos III se hicieron mojones de 2 metros de altura cuando se construyó la carretera de La Coruña para evitar que la nieve los cubriera totalmente. Por último Olagüe recuerda, en la década de 1950 en la que escribió el trabajo que aquí se cita, que no nevaba tanto como a principios del siglo $\mathrm{XX}^{92}$, si bien esta es una queja habitual también ahora, en que se dice que no nieva tanto como en los 50. Esta impresión puede ser debida a que las opiniones del presente tienden a hacer del pasado algo extraordinario y exagerado, en este caso en la cantidad de nieve, o simplemente constata un calentamiento o cambio climático a través de las sensaciones populares ante las condiciones atmosféricas. Con todo, pienso que las lluvias y las nevadas debieron ser más abundantes en la Baja Edad Media que ahora.

A través de tributos feudales y censos se puede intuir el frío de la época. Pedro González, vasallo en 1447 de Alfonso Álvarez de Toledo, señor de Cubas y Griñón, debe aportar a su señor por morar en el lugar de Horcajo diversos productos o dinero. En Navidad, el tributo consiste en dar cuatro perdices y carbón. En todo el año, es en la única ocasión que da carbón, muy necesario para calentarse del frío invierno medieval ${ }^{93}$. Otro ejemplo es el de Catalina Núñez de Toledo, mujer de Alfonso Álvarez de Toledo, que poseía desde el año 1467 un censo de 500 maravedíes al año sobre unas rentas de ejidos y carrascales, que tras sucesivas ventas y un trueque terminaría en manos del Monasterio de San Jerónimo el Real. Los pagos de las rentas se debían hacer en Navidad y Carnestolendas -Carnaval-, que sería cuando los arrendadores recaudarían el suficiente dinero para pagar el censo a su propietario, ya que justamente en esa época mucha gente pagaría por usar esos espacios buscando alimentos complementarios para el invierno y, sobre todo, buscando leña con la que encender fuego y combatir el frío - muchas casas del pueblo llano no poseían chimenea, así que harían hogueras-. Entre los alimentos complementarios, habría posiblemente más

\footnotetext{
90 Cayetano Martín, “Barajas, La Alameda, Rejas y Alcobendas”, p. 20.

91 OlagüE, Madrid y la sequía, p. 26.

92 Ibidem, pp. 26-37.

93 AVM, Minutas, 30-mayo-1447, tomo I, ff. 322r-322v.
} 
caza, casi toda caza menor, que recolección de frutos. Esos animales y las proteínas e hidratos de carbono que aportan serían también necesarios para combatir las bajas temperaturas ${ }^{94}$.

Las numerosas medidas del concejo de Madrid de control de la saca de leña en los meses de invierno nos ponen sobre la pista acerca de la necesidad de este producto ante el frío intenso que debía hacer. A modo de ejemplo, en febrero de 1484 el concejo debió ordenar que nadie trajera leña a la villa ni decepase viñas con las que hacer leña para traerla igualmente a la villa, con el fin de no perjudicar a los arrendadores de este producto ${ }^{95}$. Y a finales de diciembre de 1502, se nombraron guardas mayores para que vigilasen los montes madrileños y sancionasen a los que "tomaren deçepando e descortezando e haciendo carvón"96. Estas disposiciones pueden indicar también inviernos más fríos en esos años, si bien pienso que son normas que se estipulan de forma general para cada invierno y que su aparición responde más a una necesidad de recordar y hacer hincapié en su cumplimiento que en un aumento real del consumo de leña.

Asimismo, el concejo madrileño daba permisos a los señoríos de su Tierra para que pudiesen coger leña en su jurisdicción con la que proveerse para el invierno. En 1482 dio licencia al concejo del señorío de Polvoranca para que sus vecinos pudiesen sacar leña de los montes de Madrid, de enero a febrero, y ordenó al mayordomo de Alvar Pérez de Guzmán -titular del dominio- que trajera el documento donde se señalase el derecho que tenían de coger leña en Madrid. Mientras ratificaban tal derecho, el concejo madrileño ordenó que no se prendiera nada ni se multara a los vecinos de Polvoranca que usasen sus montes ${ }^{97}$. El mismo año de 1482, el concejo dio licencia a Pedro Gómez Barroso -titular de Parla- para que pudiese sacar desde octubre hasta Navidad dos carretadas de leña de los montes de Madrid, con destino a la casa de su señorío ${ }^{98}$.

A pesar de todas las disposiciones, normas y licencias anteriormente citadas, también hay numerosos conflictos entre Madrid y las jurisdicciones vecinas, producidos o denunciados generalmente en invierno, por las sacas de leña. Entre los enfrentamientos figuran: un pleito de Madrid frente a ciertos vecinos de Parla, a quienes fueron prendadas varias carretadas de leña que sacaban de Madrid contraviniendo la ordenanza, en enero de $1483^{99}$; la denuncia contra vecinos del señorío de Pinto que entraban en dos ejidos de Madrid a por leña, enfrentándose con armas a los guardas de esta jurisdicción ${ }^{100}$; en febrero de 1486, se denuncia que el alcaide de El Pardo, Pedro de Córdoba, entraba a pacer y a cortar leña en la Dehesa Vieja de El Pardo ${ }^{101}$; en octubre de 1500, el Real de Manzanares se queja de las talas que hacían los vecinos

\footnotetext{
94 Archivo Histórico Nacional, Clero, carpeta 1375, f. 20.

95 Libros de Acuerdos, 21-febrero-1484, I, p. 299.

96 Ibidem, 29-diciembre-1502, V, p. 79.

97 Ibidem, 29-enero-1482, I, p. 157.

98 Ibidem, 9-octubre-1482, I, p. 202.

99 Ibidem, enero-1483, I, p. 222.

100 Ibidem, 8-abril-1496, III, p. 222.

101 Ibidem, 27-febrero-1486, II, p. 11.
} 
de Madrid en el territorio que se disputaban ambas jurisdicciones ${ }^{102}$; por último, se documentan conflictos armados entre vecinos del señorío de Alcobendas y los de la aldea madrileña de San Sebastián de los Reyes, en octubre de 1506, donde se disputan términos en los que los alcobendenses habían entrado y sacado nada menos que 50.000 cargas de leña, entre otras cosas ${ }^{103}$.

Por otra parte, se producen avenencias o acuerdos entre las partes interesadas sobre la saca de leña, casi todas documentadas igualmente durante el invierno. En diciembre de 1421, Gutiérrez Fernández, Ruy Vázquez y Pedro de Vargas, no sé si a título individual o en nombre del concejo de Madrid, defendían parte del río Manzanares y del Monte de El Pardo, dejando pasar solo a las personas que les pagaban cierto precio para poder pacer con sus ganados y cortar leña, además de pescar y cazar en esa zona $^{104}$. Y el mismo mes y año de diciembre de 1421 , los vecinos de la aldea madrileña de Rabudo se avienen con dos regidores para que no les prendasen los ganados, ya que entraban en el Soto de la Pangía a pacer y a cortar leña ${ }^{105}$. La leña aparece así, de forma reiterada y desde distintos puntos de vista, como un producto muy buscado y consumido en Madrid ante el frío invernal ${ }^{106}$.

Como he hecho a lo largo de las demás estaciones climáticas, si se observan las características del sector de la construcción en Madrid, en invierno los jornales son más bajos y no se suelen estipular contratos entre noviembre y febrero. Esto da idea de unos días más cortos y un clima que dificultan la realización de las obras, al tiempo que los caminos devendrían impracticables por la nieve y el hielo para las carretas y sus pesadas cargas de piedra, madera, cal o arena. Todas estas dificultades se aprecian, también, al comprobar que el transporte de piedra desde la sierra de Guadarrama se hace en primavera y verano, y los contratos con los canteros se suelen concertar en marzo y abril y no antes ${ }^{107}$. Por la misma razón casi todas las compras de ladrillos y tejas se dan entre marzo y noviembre, ya que entre diciembre y febrero la construcción quedaría casi o totalmente paralizada ${ }^{108}$. Todos estos datos nos llevan a pensar en un tiempo de nieves y heladas más que de lluvias, puesto que en otros meses lluviosos sí se conciertan estos contratos de construcción o de transporte de materiales.

Para finalizar con este apartado, entre los numerosos topónimos de la Tierra de Madrid encontramos solo uno que hace referencia a alguna de las estaciones del año: se denomina Valdeinvierno y se encuentra en el sexmo de Aravaca. Imagino que más

102 AGS, RGS, Granada 8-octubre-1500, f. 312; Vera YAGÜE, Poblamiento, señorialización y conflictos en Madrid, pp. 1128-1129.

${ }^{103}$ AVM, Secretaría, 19-octubre-1506, Documentos sin catalogar, f. 1.

${ }^{104}$ Ibidem, Madrid 31-diciembre-1421, 3-90-1, doc. 4, f. 36.

${ }^{105}$ Ibidem, Madrid 31-diciembre-1421, 3-90-1, doc. 4, f. 54.

${ }^{106}$ Más información sobre el consumo de leña en Madrid en NiETo SÁNCHEZ, "El impacto del consumo".

107 Vera YagüE, “Un 'IPC' medieval”, p. 189.

${ }^{108}$ Esta inactividad laboral también la podemos comprobar a través de la iconografía de los meses de diciembre o febrero del calendario medieval, que apreciamos en pinturas y esculturas, donde se representan personas al fuego, comiendo o festejando, mientras que los trabajos, sobre todo los agrícolas, quedan suspendidos (CASTIÑEIRAS GonZÁLEZ, El calendario medieval hispano). 
que un valle en el que hace frío sería un espacio propicio para resguardar al ganado del frío invernal ${ }^{109}$.

\section{4. "NI ES FRÍA NI CALIENTE": LA TIERRA DE MADRID Y SU CLIMA TEMPLADO}

La Alta Edad Media europea, o al menos noreuropea, tuvo un periodo climático cálido, el "Periodo Cálido Medieval" 110 , entre el año 900 y el 1200. Ahora bien, no eran condiciones cálidas regulares, sino que los cambios en el patrón de temperaturas y precipitaciones fueron un rasgo constante del clima ${ }^{111}$. Según Fagan, las temperaturas medias de Europa serían similares a las de la actualidad, o quizás algo más bajas ${ }^{112}$. Desde 1200 empezaron a bajar las temperaturas, iniciándose así la llamada «Pequeña Edad de Hielo» o «Glacial», que se extendería hasta el siglo $\mathrm{XIX}^{113}$. En el siglo XV, el clima era difícil de pronosticar, con abundantes tormentas $\mathrm{y}$ descensos de temperaturas que continuaron hasta finales del siglo XVI ${ }^{114}$.

En la Europa meridional, el episodio cálido se caracterizaría por una abundancia de precipitaciones, por lo que para estas latitudes sería más adecuado el adjetivo de húmedo que de cálido para calificar la etapa, cuyo comienzo con respecto a la Europa traspirenaica se retrasaría en uno o dos siglos ${ }^{115}$.

Según Lorenzo Martínez para el caso español, la mayoría de los grandes fríos del altomedievo en la Península fueron debidos a irrupciones desde el noreste de aire frío continental, que afectaron principalmente a las regiones nororiental y oriental de la Península y a las Baleares. El noroeste peninsular apenas fue afectado por estas olas de frío. Así, en Galicia se sugiere la existencia de un tiempo seco y cálido (años 650-1000), y tal vez también lo fue en el centro, en Madrid. Lo vemos porque los cultivos mediterráneos irrumpen con fuerza en la Alta Edad Media en todo el norte y centro de España, ocupando durante los siglos venideros zonas anó-

109 AVM, Secretaría, Madrid 9-marzo-1480, 3-181-4; VerA YaGÜE, "Paisaje y toponimia en la Tierra de Madrid medieval", p. 242.

$110 \mathrm{Al}$ «Periodo Cálido Medieval» se le denomina también «Pequeño Óptimo Climático» o «Medieval» (Viñas Rubio, "El clima de la Tierra", p. 235).

111 El término «Periodo Cálido Medieval» fue acuñado por el meteorólogo británico Hubert Lamb, hace ya más de cincuenta años. Lamb nunca concibió ese periodo como un bloque temporal en el que Europa gozó de luz y calor, sino como una época de fluctuaciones cíclicas con inviernos ocasionalmente muy fríos, como el de 1010-1011, que afectó hasta el Mediterráneo oriental (FAGAN, El gran calentamiento, pp. 18 y 46).

112 Por el contrario, este mismo autor comenta que la temperatura media durante el «Periodo Cálido Medieval», al menos en verano, fue de $0,7^{\circ} \mathrm{C}$ a $1,0^{\circ} \mathrm{C}$ más alta que en el siglo $\mathrm{XX}$, y los veranos de la Europa central llegaban a temperaturas medias $1,4^{\circ} \mathrm{C}$ más altas que las actuales. En ese Periodo, en el sur de Europa y el Mediterráneo occidental las precipitaciones se volvieron más abundantes (FAGAN, La pequeña Edad de Hielo, p. 130).

113 La «Pequeña Edad de Hielo» no fue solo un fenómeno europeo, sino mundial (Grove y RACKHAM, The nature of Mediterranean Europe, p. 176).

114 FAgan, La pequeña Edad de Hielo, pp. 21-22; Grove y RACKHAM, The nature of Mediterranean Europe, p. 135.

115 Ferreras Fernández, Historia del clima mediterráneo, pp. 63-64. 
malas, que pasada la Baja Edad Media no volverían a alcanzar ${ }^{116}$. Este autor elige el cultivo del viñedo como prueba de clima benigno, y su abandono plantea dos posiciones: los que dicen que puede ser por un empeoramiento del clima, y los que ven una cuestión socioeconómica, de migraciones por cuestiones políticas y económicas o aumento de las importaciones de productos de fuera con mejores precios, etc. Incluso en la toponimia, por ejemplo, es interesante comprobar hasta dónde llega el topónimo viñedo; según Corominas hasta los 1.000 metros, aunque en la Edad Media se aprovechaba al máximo todo el término, incluidos los lugares más difíciles. Si hay viñedo en zonas poco propicias para ello, quiere decir que había un clima apropiado en ese momento ${ }^{117}$. Asimismo, a mediados de la decimoquinta centuria el campo compostelano seguía siendo fértil en limoneros y naranjos ${ }^{118}$.

Durante la Baja Edad Media, según numerosos especialistas en climatología histórica ${ }^{119}$, se daría una etapa algo más cálida en el sur de Europa frente al enfriamiento del clima que se produjo en el norte del continente, con un siglo XV especialmente lluvioso en la península Ibérica, en la que se pasaría a una etapa más fría desde el siglo XVI. A partir de este momento nuestra península se sumaba a la «Pequeña Edad de Hielo» que ya había comenzado siglos atrás en la Europa septentrional ${ }^{120}$. Así lo aprecia también Ángel Carrasco en su trabajo sobre el clima en Alcalá de Henares ${ }^{121}$, o lo apreciamos a lo largo de este artículo donde he citado varias heladas -que no nieves- para esta última centuria en el entorno madrileño.

Centrando nuevamente el análisis en Madrid a través de las Relaciones de Felipe II, estas hablan de forma general de las temperaturas medias de los pueblos, aunque como siempre sus respuestas son apreciaciones de los vecinos sobre el clima de los lugares donde viven. Casi todos dicen o vienen a decir que viven en un clima templado, en "tierra templada", y muchos especifican también que no es totalmente la suya ni una tierra fría ni cálida, sino que dependía de la época. Recordemos algo obvio, que la península Ibérica y, por ende, Madrid, pertenecen a la zona templada -más concretamente templada-cálida- del planeta. Pero bueno, mejor que descrito por mí que lo describan los habitantes de las aldeas madrileñas: los de Getafe dicen que "la tierra ni es fría ni caliente, porque en el tiempo de las grandes calores, no tira mucho la gran calor, ni el yelo dura mucho invierno, aunque unos inviernos yela más que otros"; esto es, hay inviernos más fríos que otros y hay más heladas en unos que en otros, como es lógico. Los vecinos de Perales dicen que su aldea "está en tierra fría porque es arena, y antes peca de enferma que de sana por razón que el río [Manzanares] y unos charcos, que el dicho pueblo tiene junto con él...

116 MARTínez ÁnGel, "El viñedo en la montaña oriental leonesa”, p. 71.

117 Ibidem.

118 Font Tullot, Historia del clima en España, p. 66.

119 Entre esos muchos especialistas se encuentran: GARCía Cordón, Un clima para la Historia, pp. 58 y 60; Ferreras Fernández, Historia del clima mediterráneo, pp. 65-66; Font Tullot, Historia del clima en España, pp. 62-66.

120 Grove y Rackham plantean 4 fases para la «Pequeña Edad de Hielo»: La primera desde principios del siglo XIV, la segunda desde finales del siglo XVI, la tercera desde finales del siglo XVII, y la cuarta desde principios del siglo XIX. La península Ibérica entraría en esta fase fría climática desde la segunda fase (GROVE y RaCKHAM, The nature of Mediterranean Europe, p. 138).

121 Carrasco Tezanos, "El clima en la meseta sur y la comarca de Alcalá". 
y también es algo cálido de agosto y otoño". Los de Boadilla del Monte dicen que su lugar "es en invierno frío y en verano caliente". Los de Canillas dicen que son "tierra templada", y los vecinos de Canillejas, cercana a la anterior, matizan que el suyo es lugar "algo más frío que caliente" ${ }^{122}$. Los vecinos de Hortaleza y de su vecina Fuencarral señalan que las suyas son tierras templadas de invierno y de verano, los de Ribas dicen que su aldea a orillas del Manzanares "es tierra no fría ni caliente, de buen temple", y los de Aravaca, aldea cercana a la sierra, señalan que "la tierra del dicho lugar es templada, no demasiada fría en invierno, ni demasiada de caliente en verano"123. Para no ser repetitivo, en las Relaciones casi todos los pueblos dan estas respuestas o similares, excepto curiosamente las aldeas de Fuenlabrada y Humanejos y la villa señorial de Polvoranca, situadas al sur de Madrid y más alejadas de la sierra, que dicen que son tierras frías, matizando algunas que son además húmedas y llanas. Estas tres localidades están cercanas entre ellas, y tal vez los llanos donde se sitúan y los arroyos o acuíferos que las recorren las harían tener ese clima, al menos en invierno ${ }^{124}$. Por el contrario los vecinos de Rejas, cercana al río Manzanares y a Barajas y La Alameda -cuyos vecinos, tal como vimos en otros apartados, decían que eran tierras frías por su cercanía a la sierra-, dicen que "la calidad de esta tierra es cálida" 125 .

Otro aspecto muy relacionado con las variaciones climáticas estacionales es el del ganado trashumante. El ganado ovino madrileño que realizaba la trashumancia solía trasladarse hacia el sur en otoño, entre finales de octubre y noviembre, para pasar el invierno en La Mancha o en la Andalucía septentrional. Retornaban esos rebaños hacia el norte entre marzo y abril, y la veranada solían permanecer en territorio madrileño. Por otro lado, el ganado ovino foráneo y trashumante, que pasaba por Madrid a través de las cañadas reales, no permanecía aquí ni en invierno ni en verano $^{126}$. Estos datos ofrecen otra evidencia climática, y es que la zona de Madrid era especialmente fría en invierno y cálida en verano, aunque en este caso no tanto como el sur peninsular, con lo que las temperaturas frías invernales no permitirían la existencia de pastos, mientras que las estivales sí -al menos en determinadas zonas menos secas, como las situadas en torno a la sierra de Guadarrama-, por lo que algunos propietarios madrileños de ovejas se quedaban a pasar la veranada en su tierra. Esta circunstancia se produce también en el clima actual. Madrid, a pesar de tener una amplitud térmica anual grande entre los meses más fríos y los más cálidos, no llega en ningún caso a temperaturas invernales tan bajas como en la submeseta norte, o estivales tan altas como en el sur de la península. Esto es debido a la latitud intermedia en la que se encuentra Madrid con respecto a la submeseta norte y a La Mancha y Andalucía, y a la altitud en la que se encuentra la submeseta sur, donde se halla Madrid, que es menor si la comparamos con la submeseta norte y, por tanto, menos fría, y mayor si la comparamos con Andalucía.

122 ViÑas y Mey y PaZ y Remolar, Relaciones histórico-geográfico-estadísticas, pp. 105, 149, 154, 286 y 441.

${ }^{123}$ Ibidem, pp. 77, 257, 318 y 524.

${ }^{124}$ Ibidem, pp. 266, 331 y 475.

${ }^{125}$ Ibidem, p. 506.

126 PuÑal Fernández, “La ganadería lanar”, pp. 338-339 y 348-349. 


\section{TÉRMINOS Y CONCEPTOS MEDIEVALES RELATIVOS AL CLIMA Y A LA METEOROLOGÍA}

Aunque muchas veces las denominaciones son distintas que en la ciencia actual, se puede apreciar cómo en la Edad Media se tenían claros muchos conceptos relacionados con la meteorología y la climatología, esto es, con el tiempo y el clima, si bien usando otras palabras y sistematizando los datos climáticos de forma diferente. Asimismo, aplican los conocimientos meteorológicos y climatológicos a cuestiones prácticas, como la caza o el registro y reparación de daños en edificios. Todos los términos recopilados a continuación han sido extraídos de las mismas fuentes usadas a lo largo de este artículo: la mayoría del Libro de la Montería ${ }^{127} \mathrm{y}$, en menor medida, de otros documentos medievales referidos a Madrid.

El listado de términos meteorológicos y climatológicos que aparecen en el Libro de la Montería es el siguiente, con su significado o posible significado:

-"Verano": estación del año que, en la Edad Media, iría de abril a septiembre, conformada por la primavera y verano actuales.

-"Estío": estación de pleno verano, de junio a agosto, en la que no sé si incluiría a septiembre o a al menos una parte de este mes. Tal vez determine simplemente el periodo más árido y cálido del verano, que entonces puede variar cada año en cuanto a los meses o semanas que lo componen.

-“Otoñada": estación que, en los siglos estudiados en este trabajo, se corresponde seguramente con el mes de septiembre y las primeras semanas del otoño -no con todo el otoño-.

-"Invierno": estación del año que, en la Edad Media, iría de octubre a marzo, conformada por el otoño e invierno actuales.

-“Calenturas": temperaturas cálidas.

-“Caliente": temperatura cálida.

-"Friura": temperaturas frescas, frescor.

-"Frío": temperatura fría.

-"Tiempo": hay que hacer notar que usan esta palabra igual que ahora, no solo para hablar del tiempo cronológico y del paso del tiempo, sino también del tiempo meteorológico, con las condiciones de temperatura y precipitaciones, que es el tiempo que nos interesa en el presente trabajo.

-“Tiempo de/del verano": características climáticas habituales, de temperatura y precipitaciones, que se dan en el verano medieval, de abril a septiembre.

-"Tiempo de/del estío": características climáticas habituales, de temperatura y precipitaciones, que se dan en el momento álgido del verano, cuando es más seco y caluroso, de junio a septiembre.

${ }^{127}$ El Libro de la Montería es una fuente consultada en multitud de trabajos de investigación, sobre todo por parte de historiadores españoles para la descripción de los paisajes y topónimos medievales de muchas zonas de Castilla, o para analizar la vegetación de esta época. También investigaciones foráneas citan y usan frecuentemente esta fuente (Grove y RACKHAM, The nature of Mediterranean Europe, p. 176). Sin embargo, muchos de ellos no han reparado lo suficiente en la información tan rica que el Libro nos aporta acerca del clima. 
-"Tiempo caliente": tiempo cálido.

-“Tiempo muy caliente”: tiempo muy cálido.

-“Tiempo de nieve": tiempo de nevadas.

-“Tiempos de los muchos hielos": tiempo muy frío y seco, con heladas.

-“Tierras tempradas": características de las zonas y de los suelos cuando el clima se muestra templado, con una temperatura moderada, que suele coincidir con una mayor humedad en la atmósfera y en dichos suelos.

-"Tierras calientes": características de las zonas y de los suelos cuando el clima se vuelve más cálido.

-"Tierras frías": características de las zonas y de los suelos cuando el clima se vuelve más frío.

-“Tierras livianas": ¿tierras secas? ¿o templadas también?

-"Secas": sequías, suele ir en plural: tiempo seco, árido, de pocas lluvias y humedad.

-"Nieblas": niebla, aunque suele denominarse en plural.

-"Niebla alta": niebla a cierta altura; lo contrario sería niebla baja, a ras de suelo.

-"Niebla cerrada y non cerrada": niebla densa o no tan densa.

-"Rocío", "haya rociado": vapor que con el frío de la noche se condensa en la atmósfera en gotas muy menudas, y se posan sobre plantas y suelos.

-"Rocío" y "siesta": la mañana y la tarde, respectivamente.

-"Lluvia" y "Lluvias": precipitaciones en forma de agua; en singular suele señalar un momento puntual de precipitaciones, y en plural suele indicar un periodo de precipitaciones.

-"Nieve": precipitaciones de agua solidificada por el frío en forma de copos de nieve.

-"Hielo", "hielos" y "heladas": Agua solidificada a causa del frío en forma de hielo.

-"Viento" y "grand viento": el mismo significado que ahora, aire en movimiento, y viento muy fuerte en el segundo caso.

-“Día muy claro et muy asosegado sin viento": día de calma atmosférica.

Es asimismo muy importante concretar el vocabulario de la gente de la Edad Media cuando se refiere a lluvias o solo a crecidas de ríos, ya que estas pueden venir provocadas por lluvias, pero también como consecuencia del deshielo, etc. En estos casos es fundamental distinguir unas causas de otras, aunque a simple vista tendamos a encuadrarlas todas por igual en un tiempo lluvioso, que como hemos visto en este artículo no tiene por qué ser así. La terminología sobre estos aspectos que se expone en los siguientes párrafos está extraída de expresiones recogidas en las fuentes documentales locales o generales referidas a Madrid.

Cuando llueve, sobre todo cuando lo hace en abundancia, la documentación suele hablar de "aguas" en plural, porque suele referirse a muchos días o incluso meses de precipitaciones, y alguna vez habla de "agua", en este caso porque las lluvias han caído en un día y momento concretos. Y "nieves" cuando, obviamente, las 
precipitaciones han caído de esa forma a lo largo de un periodo determinado. Todo ello viene recogido en frases como: "las grandes aguas que hiso", "que las muchas aguas", "con las muchas aguas", "con el agua que hizo [el domingo]", "tan grande fortuna de aguas e nieves" 128 .

Por otro lado, cuando son inundaciones por crecidas de ríos suele indicarlo con el término "avenidas" o de otra forma que exprese que el río ha subido su caudal habitual: "el agua en estas abenidas pasadas", "el río se avía llevado", "que el río cresca", "las abenidas", "con las grandes avenidas" 129.

\section{CONCLUSIONES Y REFLEXIONES FINALES}

Antes de pasar a las conclusiones, quisiera resumir en el siguiente elenco todas las incidencias referidas a las precipitaciones y crecidas de ríos, señaladas en este artículo para la Baja Edad Media -aunque sin recoger las reseñadas para la segunda mitad del siglo XVI-, a las que añado otras de las que no conozco más que el año en que ocurrieron, y no el mes o los meses, por lo que no las había puesto antes. Por eso, solamente sobre estas últimas pongo la referencia documental y no de todas, con el fin de no resultar repetitivo. Con este listado de circunstancias meteorológicas documentadas para Madrid y sus alrededores junto a los años, y muchas veces meses, en las que acaecieron se puede observar, de un solo vistazo, los fenómenos meteorológicos acaecidos en Madrid en el periodo analizado:

-1345: año de nieves y hielos en toda Castilla ${ }^{130}$.

-1346: sequía ${ }^{131}$.

-1347: fuertes temporales ${ }^{132}$.

-1351: malos temporales en Castilla ${ }^{133}$.

-1414: sequía ${ }^{134}$.

-1426: sequía ${ }^{135}$.

-1427: lluvias y crecidas ${ }^{136}$.

-Finales de octubre de 1434 a enero de 1435: lluvias y nieves.

-Finales de octubre de 1438 a enero de 1439: lluvias.

128 AGS, RGS, Toledo 16-mayo-1498, f. 126; Libros de Acuerdos, 18-abril-1489, II, p. 138; AGS, RGS, Granada 15-septiembre-1499, f. 7; Libros de Acuerdos, 7-julio-1514, V, p. 288; Crónica de Juan II de Hernán Pérez de Guzmán, en IzQuierdo Benito, Precios y salarios en Toledo, p. 42.

129 Libros de Acuerdos, 7-febrero-1481, I, p. 70; Libros de Acuerdos, 5-abril-1484, I, p. 313; Libros de Acuerdos, 13-abril-1489, II, p. 136; Libros de Acuerdos, 13-febrero-1492, II, p. 323; AGS, RGS, Toledo 14-febrero-1487, f. 45.

${ }^{130}$ Montero Vallejo, "Un siglo de crisis en Madrid”, p. 122.

131 Vera Yagüe, Territorio y población en Madrid, p. 30; Font Tullot, Historia del clima en España, p. 63.

132 Montero Vallejo, "Un siglo de crisis en Madrid", p. 123.

133 Ibidem, p. 122.

134 Vera YagüE, Territorio y población en Madrid, p. 30; Font Tullot, Historia del clima en España, p. 64.

135 Idem; Idem; Montero Vallejo, "Un siglo de crisis en Madrid", p. 123.

136 Vera YagüE, Territorio y población en Madrid, p. 30; JimÉnez RaYAdo, El agua en el origen, p. 154. 
-Octubre de 1449: lluvias

-Junio de 1451: crecidas de ríos.

-Enero-febrero de 1481: crecidas de ríos.

-Febrero de 1484: crecidas de ríos.

-Marzo-abril de 1484: crecidas de ríos.

-1486: crecidas, por lluvias, del río Humanejos, que destrozan unas huertas ${ }^{137}$.

-¿Abril, o antes, de 1489?: crecidas de ríos.

-Abril de 1489: lluvias.

-Febrero de 1492: crecidas de ríos.

-Invierno de 1498-1499: lluvias.

-6 de julio de 1514: lluvia.

-1530: heladas en el Tajo.

-1536: heladas en el Tajo.

Con todos estos datos y lo analizado a lo largo del presente artículo se podrían dar algunas claves, con todas las cautelas, del clima de Madrid y, por extensión, de la Castilla central en la Baja Edad Media:

- Las lluvias caen fundamentalmente en primavera, en otoño -más en la segunda parte de esta estación-, y en invierno -junto a las nieves-, con un periodo de sequía estival. Esto es, casi igual que en la actualidad. Es difícil saber si sería mayor o menor la cantidad caída de agua antes que ahora. Y, aunque ya vimos que era una hipótesis cuestionable, el uso de bueyes de labranza que poseen una mayor potencia de trabajo podría deberse a las tierras húmedas y pesadas, causadas, tal vez, por las abundantes lluvias primaverales y otoñales, pasando al uso de mulas para la misma tarea agrícola desde el siglo XVI ante el aumento de las roturaciones y, quién sabe, si ante una tierra menos pesada por la disminución de esas mismas lluvias; una disminución de precipitaciones en la decimosexta centuria que podría deberse también al aumento del frío y, con ello, el desarrollo de un tiempo más seco. Por otra parte, el menor número de rogativas pro-pluvia en Madrid en el siglo XV que en el XVI, ayudaría a corroborar lo antedicho. Todo lo expuesto podría hacernos pensar en unas precipitaciones más cuantiosas en la Baja Edad Media, aunque con respecto al siglo XVI y no necesariamente con respecto al presente. De hecho, según Font al menos una tercera parte del siglo XV fue muy lluvioso en la Meseta ${ }^{138}$.

- $\quad$ El verano, como ahora, era una estación calurosa y seca, donde se producía el menor número de precipitaciones de todo el año, exceptuando alguna que otra lluvia aislada y torrencial. El estío, con cuyo término se definía en la Edad Media, seguramente, a la fase más seca del verano, abarcaría, también probablemente, el periodo que va desde el mes de junio hasta la primera veintena de agosto. En el siglo XVI se documentan numerosos episodios de lluvias torrenciales a finales del verano, esto es, en septiembre. Tal vez fueran precipitaciones causadas por aportes de vapor de agua arrastrados desde el Mediterráneo, o bien lluvias de convección provocadas

137 AGS, RGS, Toledo 14-febrero-1487, f. 45; AGS, RGS, Toledo 16-mayo-1498, f. 126.

138 Font Tullot, Historia del clima en España, p. 64. 
por la acumulación y ascenso puntual de aire caliente y húmedo, cuya humedad provendría del vapor de agua producido de forma rápida por la evaporación intensa propia de esta estación.

En otoño se documentan algunas lluvias en el siglo XV, mientras que el siglo XVI aparece más bien como un periodo seco y caluroso, al menos durante las primeras semanas de esta estación, cuyo periodo suele denominarse en la documentación de esta centuria como "otoñada"-probablemente abarca los meses de septiembre y octubre-. Si extrapolamos los datos de esta decimosexta centuria a la Baja Edad Media, nos hablarían tal vez de un otoño medieval más bien seco y cálido, al menos en la parte inicial de esta estación. Aunque también debemos recordar una vez más que el siglo XVI es más frío y, por tanto, más seco.

- $\quad$ En invierno se dan episodios de lluvias y nevadas, posiblemente mucho más abundantes que en la actualidad. Las nieves se anticiparían, tal vez, incluso a noviembre, extendiéndose hasta enero o quién sabe si hasta febrero. En la actualidad los episodios de nieves serían cuantitativamente menores, y se darían sobre todo entre diciembre y enero.

- $\quad$ Las temperaturas son más difíciles aún de cuantificar para la Edad Media, si bien se seguirían dando las mismas características generales que en la actualidad: frío en invierno, calor en verano, paso del frío al calor en primavera y del calor al frío en otoño, aunque como vimos antes predomine tal vez más el calor que el frío a lo largo de esta última estación. La cercanía de la sierra de Guadarrama también influiría en una mayor frialdad en el invierno que en otras zonas del interior no tan próximas a las montañas. Todo ello nos remite a un clima típico de la zona templada de la Tierra donde se distinguen perfectamente las cuatro estaciones del año, frente a los climas fríos y sobre todo cálidos, donde las estaciones son mucho más homogéneas, en las que predomina siempre el frío en los primeros y el calor en los segundos.

- Los cultivos principales de la Tierra de Madrid son parte de la trilogía mediterránea: cereal, sobre todo, y vid, mientras que el olivo no se documenta. Unos cultivos propicios para el clima mediterráneo de interior y mesetario.

- Con todas estas características, se podría asegurar que el clima en esta época es un clima mediterráneo, al igual que en el presente: un clima mediterráneo continentalizado. Sin embargo, este clima mediterráneo podría tener algunas variantes, entre las que podría estar un mayor frío en invierno -con más nevadas- que en la actualidad, y quién sabe si más calor en otoño. Esto es, un clima con contrastes iguales o más grandes que ahora entre sus estaciones. También se aprecian en los trabajos de Alvar o Carrasco, aunque con series del siglo XVI, periodos de cinco o seis años de pocas lluvias y sequía, seguidos de uno o dos de abundantes lluvias, que es un ciclo típico que se repite en el clima mediterráneo.

Por último, todo este trabajo propicia otra serie de reflexiones, entre las que podríamos destacar:

- La extrema dificultad de estudiar el clima en la Edad Media. La documentación sobre este tema es muy escasa, es difícil hacer con ella series continuadas y, sobre todo, es poco elocuente en cuanto a datos cuantitativos. Para mayor complicación el año lo dividen en esta época en dos estaciones, así que cuando solo se docu- 
menta que ocurrieron una serie de hechos meteorológicos en una de esas estaciones dificulta concretar en qué mes o periodo acaecieron.

- Siguiendo el argumento anterior, determinar las diferencias del clima actual con el de la Edad Media, con las que se podría intentar aportar más datos a la realidad del cambio climático, es muy difícil de hacer documentalmente.

- $\quad$ El hombre medieval conoce y usa conceptos meteorológicos y climatológicos para aplicarlos a la vida práctica y cotidiana. Son un instrumento funcional más con el que manejarse en su mundo, el cual está estrechamente vinculado a la naturaleza.

- En definitiva, el presente trabajo más que dar respuestas plantea preguntas. Aún así, deduciendo mucho e intuyendo otro tanto, algo se ha podido contar. Además, se han aportado algunos métodos de análisis climáticos, susceptibles de ser utilizados para otros estudios similares en otras zonas.

\section{BIBLIOGRAFÍA}

Alvar Ezquerra, Alfredo; García Guerra, Elena; Zofío Llorente, Juan Carlos; Prieto Palomo, Teresa; y Zozaya Montes, Leonor, "Clima, técnica y poderes. Madrid, 15611598”, Revista de Historia Moderna, 23 (2005), pp. 135-184. URL: http://digital.csic.es/ bitstream/10261/14828/1/RHM_23_06.pdf

Bullón MATA, Teresa, “Avenidas fluviales y precipitaciones en las cuencas de los ríos Jarama-Tajo al final del siglo XVI", Boletín de la Asociación de Geógrafos Españoles, 60 (2012), pp. 77-90. URL: http://www.boletinage.com/articulos/60/04-BULLON.pdf

Carrasco Tezanos, Ángel, "El clima en la meseta sur y la comarca de Alcalá, 1300-1600", en Cristina Segura (coord.), Clima y medio ambiente en las tierras de Madrid en la Edad Media, Colección Laya nº 41, Madrid: A.C. Almudayna, 2015, pp. 101-121.

Carrasco Tezanos, Ángel y Vera Yagüe, Carlos Manuel, "La organización social del espacio y el redescubrimiento de la Edad Media en la historiografía sobre Madrid y su Comunidad de los últimos veinticinco años", en Grupo Taller de Historia Social, Veinticinco años después. Avances en la Historia Social y Económica de Madrid, Madrid: Universidad Autónoma de Madrid, 2014, pp. 75-104.

Cayetano Martín, María del Carmen, "Barajas, La Alameda, Rejas y Alcobendas según las Respuestas Generales del Catastro de Ensenada", Alcabala del viento: Barajas, Alcobendas (1751), según las Respuestas Generales del Catastro de Ensenada, Madrid, 1995, pp. 17-73.

CastiñeIras GonzÁlez, Manuel Antonio, El calendario medieval hispano, Salamanca: Junta de Castilla y León, 1996.

Clemente Ramos, Julián, La economía campesina en la Corona de Castilla (1000-1300), Barcelona: Crítica, 2004.

Covarrubias Orozco, Sebastián, Tesoro de la lengua castellana, o española, Impreso por Luis Sánchez, Madrid, 1611. URL: http://fondosdigitales.us.es/fondos/libros/765/16/ tesoro-de-la-lengua-castellana-o-espanola/

Creus, José; Peña, José Luis; Barriendos, Mariano; Moreno, Ana; GonzÁlez, Penélope; Sancho, Carlos; Valero, Blas; Pérez, Augusto; Saz, Miguel Ángel; y Constante, Ana, "Los estudios de Paleoclimatología en España", en José María Cuadrat y Javier Martín 
Vide (coords.), La climatología española: pasado, presente y futuro, Zaragoza: Prensas Universitarias de Zaragoza, 2007, pp. 249-281.

De Miguel Rodríguez, Juan Carlos, "Incidencia del clima en el paisaje andaluz bajomedieval. El Reino de Granada", Andalucía entre Oriente y Occidente (1236-1492). Actas del V Coloquio Internacional de Historia Medieval de Andalucía, Córdoba, 1988, pp. 733-743.

FAgan, Brian M., La pequeña Edad de Hielo. Cómo el clima afectó a la historia de Europa (1300-1850), Barcelona: Gedisa, 2008.

FAGAN, Brian M., El gran calentamiento: cómo influyó el cambio climático en el apogeo y caída de las civilizaciones, Barcelona: Gedisa, 2009.

Ferreras Fernández, Calixto, Historia del clima mediterráneo, Murcia: Consejería de Agricultura y Agua de la Región de Murcia, 2005.

Font Tullot, Inocencio, Historia del clima en España. Cambios climáticos y sus causas, Madrid: Instituto Nacional de Meteorología, 1988.

García Cordón, Juan Carlos, Un clima para la Historia ... una Historia para el clima, Santander: Universidad de Cantabria, 1996.

Grove, A. T. y Rackham, Oliver, The nature of Mediterranean Europe. An ecological History, Yale University Press, 2003.

IzQUIERdo BEnITO, Ricardo, Precios y salarios en Toledo durante el siglo XV (1400-1475), Toledo: Caja de Ahorro Provincial de Toledo, 1983.

JiMÉNEZ RAYADO, Eduardo, El agua en el origen y desarrollo de Madrid en la Edad Media, Colección Laya $n^{\circ}$ 34, Madrid: A.C. Almudayna, 2011.

JiMÉNEZ RAYADO, Eduardo, "El agua imaginada: rogativas y peticiones de lluvia en el Madrid medieval", en María Isabel del Val Valdivieso (ed.), La percepción del agua en la Edad Media, Alicante, 2015, pp. 277-312.

Libro de La Montería del rey Don Alfonso XI (siglo XIV), con un discurso y notas del Excmo. Señor D. José Gutiérrez de la Vega, Biblioteca Venatoria de Gutiérrez de la Vega, 2 vols. Madrid, 1877. Versión facsímil, Madrid, 1983. URL: http://bibliotecadigital.jcyl. es/i18n/catalogo_imagenes/grupo.cmd?path=10079166

Libros de Acuerdos del Concejo madrileño, 1464-1600. Vol. I. Años 1464-1485, A. Millares - J. Artiles (eds.), Madrid, 1932.

Libros de Acuerdos del Concejo madrileño, 1464-1600. Vol. II. Años 1486-1492, A. Gómez (ed.), Madrid, 1970.

Libros de Acuerdos del Concejo madrileño, 1464-1600. Vol. III. Años 1493-1497, C. Rubio et. al. (eds.), Madrid, 1979.

Libros de Acuerdos del Concejo madrileño, 1464-1600. Vol. IV. Años 1498-1501, C. Rubio et. al. (eds.), Madrid, 1982.

Libros de Acuerdos del Concejo madrileño, 1464-1600. Vol. V. Años 1502-1515, R. Sánchez - Ma C. Cayetano (eds.), Madrid, 1987.

MARTínez Ángel, Lorenzo, "El viñedo en la montaña oriental leonesa en los siglos X y XI. Aproximación a la historia del clima", Iacobus, 2 (1996), pp. 69-85.

Montero Vallejo, Manuel, "Un siglo de crisis en Madrid (1346-1453)”, Torre de los Lujanes, 23 (1993), pp. 121-134. 
Morales Valverde, Ramón, Flora literaria del Quijote, alusiones al mundo vegetal en las obras completas de Cervantes, "Instituto de Estudios Albacetenses «Don Juan Manuel»”, Albacete, 2005. URL: http://digital.csic.es/bitstream/10261/71520/1/275MORA LES_Flora_Quijote.pdf

NiETo SÁnCHEZ, José Antolín, "El impacto del consumo de combustible de Madrid sobre su territorio", en Cristina Segura (coord.), Clima y medio ambiente en las tierras de Madrid en la Edad Media, Colección Laya n 41, Madrid: A.C. Almudayna, 2015, pp. 67-87.

OlagüE, Ignacio, Madrid y la sequía, Temas madrileños XIV, Madrid: Instituto de Estudios Madrileños, 1955.

Ortega Cervigón, José Ignacio, "La medida del tiempo en la Edad Media. El ejemplo de las crónicas cristianas", Medievalismo, 9 (1999), pp. 9-39. URL: https://digitum.um.es/ xmlui/bitstream/10201/35492/1/52321-222901-1-PB.pdf

Puñal Fernández, Tomás, "La ganadería lanar en Madrid y su tierra durante la Edad Media", Espacio, Tiempo y Forma. Serie III, Historia Medieval, 11 (1998), pp. 331-381. URL: ttp://e-spacio.uned.es/fez/eserv.php?pid=bibliuned:ETF1CA0F818-F0FF-5AC38C4D-71D38ADBCEFA\&dsID=Documento.pdf

Puñal FERnÁnDEZ, Tomás, El registro de la documentación notarial del Concejo de la Villa y Tierra de Madrid (1449-1462), Madrid: Consejería de Cultura y Deportes de la CAM, 2005.

Relaciones topográficas de Felipe II: Madrid, Alfredo Alvar Ezquerra (coord.), 3 vols., Madrid, 1993.

Rodríguez Morales, Jesús, "Viabilidad invernal en el Puerto de la Fuenfría. Nieve y hielo en las épocas Antigua, Medieval y Moderna”, en Cristina Segura (coord.), Clima y medio ambiente en las tierras de Madrid en la Edad Media, Colección Laya n 41, Madrid: A.C. Almudayna, 2015, pp. 135-154.

SABATÉ I CUrull, Flocel, "Natura i desenvolupament. L'espai natural a l'Edat Mitjana", Natura y desenvolupament. El medi ambient a l'Edat Mitjana, Lleida, 2007, pp. 9-27.

VÁzQuez FERnÁNDEZ, Luis, "De cómo Tirso se ríe del río Manzanares”, en Francisco Domínguez Matito y María Luisa Lobato López (coords.), Memoria de la palabra: Actas del VI Congreso de la Asociación Internacional Siglo de Oro, vol. 2, Madrid-Frankfurt, 2004, pp. 1795-1803. URL: http://cvc.cervantes.es/literatura/aiso/pdf/06/aiso_6_2_074. pdf

Vera Yagüe, Carlos Manuel, Territorio y población en Madrid y su Tierra en la Baja Edad Media. La señorialización del espacio madrileño y la repoblación concejil "antiseñorial” en los siglos XIV a XVI, Colección Laya n 21, Madrid: A.C. Almudayna, 1999.

Vera Yagüe, Carlos Manuel, Poblamiento, señorialización y conflictos en Madrid y su Tierra en la Baja Edad Media, Tesis Doctoral, Universidad Autónoma de Madrid, 2004. URL: https://repositorio.uam.es/handle/10486/12860

Vera Yagüe, Carlos Manuel, "Paisaje y toponimia en la Tierra de Madrid medieval”, en Eduardo Jiménez e Ignacio Sánchez (eds.), El paisaje madrileño. De Muhammad I a Felipe II, Colección Laya nº 35, Madrid: A.C. Almudayna, 2013, pp. 217-276.

Vera Yagüe, Carlos Manuel, 'Un 'IPC' medieval: precios, rentas y salarios en Madrid a mediados del siglo XV (1440-1449)", en Santiago Muriel (coord.), Cultura material en las tierras de Madrid en la Edad Media, Colección Laya nº 36, Madrid: A.C. Almudayna, 2014, pp. 157-249. 
Viñas Rubio, José Miguel, "El clima de la Tierra a lo largo de la Historia”, en Armando Alberola Romá (coord.), Clima, naturaleza y desastre. España e Hispanoamérica durante la Edad Moderna, Valencia: Universitat de València, 2013, pp. 225-239. URL: http:// www.divulgameteo.es/uploads/Clima-Tierra-historia-JMV.pdf

VIÑas y Mey, Carmelo y Paz y Remolar, Ramón, Relaciones histórico-geográfico-estadísticas de los pueblos de España ordenadas por Felipe II. Provincia de Madrid, Madrid: CSIC, 1949. 